\title{
Predictability and Prediction of Southern California Rains during Strong El Niño Events: A Focus on the Failed 2016 Winter Rains
}

\author{
TAO ZHANG \\ Cooperative Institute for Research in Environmental Sciences, University of Colorado Boulder, and Physical \\ Sciences Division, NOAA/Earth System Research Laboratory, Boulder, Colorado \\ MARTIN P. HOERLING \\ Physical Sciences Division, NOAA/Earth System Research Laboratory, Boulder, Colorado \\ KLAUS WOLTER, JON EISCHEID, AND LINYIN CHENG \\ Cooperative Institute for Research in Environmental Sciences, University of Colorado Boulder, and Physical Sciences \\ Division, NOAA/Earth System Research Laboratory, Boulder, Colorado \\ ANDREW HOELL \\ Physical Sciences Division, NOAA/Earth System Research Laboratory, Boulder, Colorado \\ Judith Perlwitz, XiaO-Wei Quan, AND JosePh BARSUgli \\ Cooperative Institute for Research in Environmental Sciences, University of Colorado Boulder, and Physical Sciences \\ Division, NOAA/Earth System Research Laboratory, Boulder, Colorado
}

(Manuscript received 9 June 2017, in final form 7 September 2017)

\begin{abstract}
The failed Southern California (SCAL) winter rains during the 2015/16 strong El Niño came as a surprise and a disappointment. Similarities were drawn to very wet winters during several historical strong El Niño events, leading to heightened expectations that SCAL's multiyear drought would abate in 2016. Ensembles of atmospheric model simulations and coupled model seasonal forecasts are diagnosed to determine both the potential predictability and actual prediction skill of the failed rains, with a focus on understanding the striking contrast of SCAL precipitation between the 2016 and 1998 strong El Niño events. The ensemble mean of simulations indicates that the December-February 2016 winter dryness was not a response to global boundary forcings, which instead generated a wet SCAL signal. Nor was the extreme magnitude of observed 1998 wetness entirely reconcilable with a boundary-forced signal, indicating it was not a particularly precise analog for 2016. Furthermore, model simulations indicate the SCAL 2016 wet signal was $20 \%-50 \%$ less intense than its simulated 1998 counterpart. Such a weaker signal was captured in November 2015 initialized seasonal forecasts, indicating dynamical model skill in predicting a less prolific 2016 rainy season and a capability to forewarn that 2016 would not likely experience the flooding rains of 1998 . Analysis of ensemble spread indicates that 2016 dryness was an extreme climate event having less than $5 \%$ likelihood in the presence of 2016 global forcings, even though its probability of occurrence was 3-4 times greater in 2016 compared to 1998. Therefore, the failed seasonal rains themselves are argued to be primarily a symptom of subseasonal variability unrelated to boundary forcings whose predictability remains to be explored.
\end{abstract}

\section{Introduction}

Drought conditions developed in California during 2011/ 12 , gradually worsening to reach exceptional severity by 2015 (Diaz and Wahl 2015; Seager et al. 2015). Widespread

Corresponding author: Dr. Tao Zhang, tao.zhang@noaa.gov impacts included excess groundwater pumping to irrigate existing agricultural fields, hundreds of thousands of acres remaining fallow nevertheless, and the most severe wildfire season on record for the United States in 2015 (NOAA 2017). During the summer and fall of 2015, this excessive dryness set the stage for a highly anticipated winter rainy season in Southern California (SCAL). 


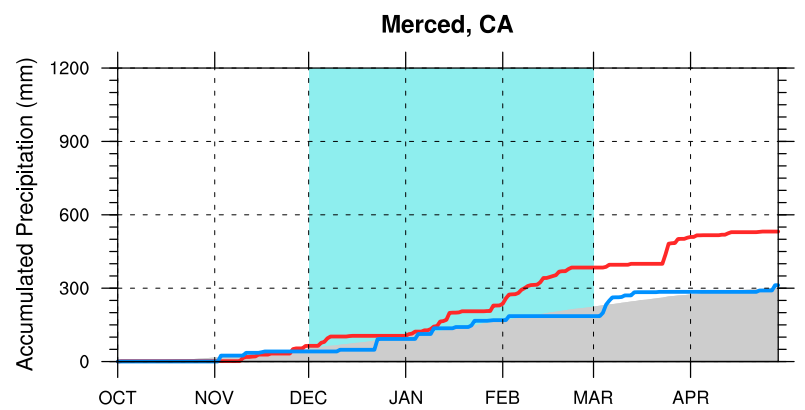

Santa Barbara, CA

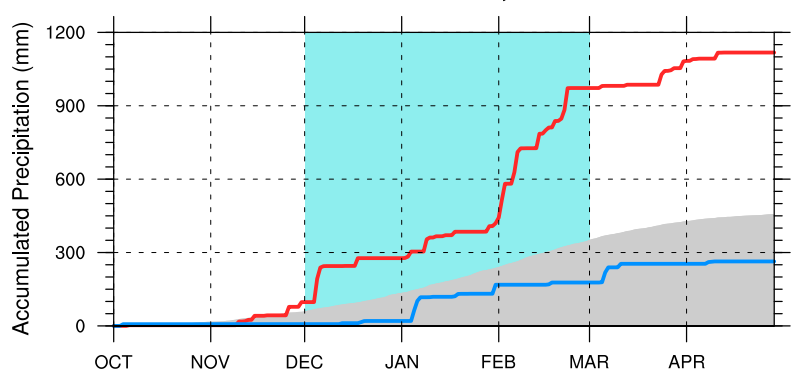

Riverside, CA

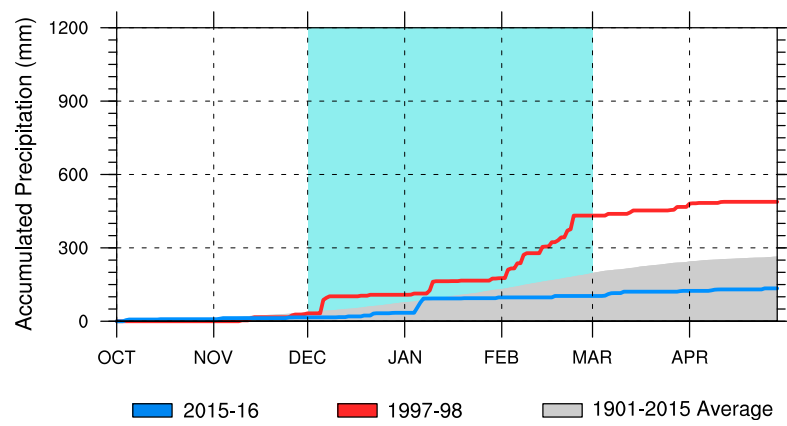

FIG. 1. Daily time series of observed cumulative precipitation for three California stations that transect the SCAL region used in this study: Merced $\left(37^{\circ} \mathrm{N}, 120^{\circ} \mathrm{W}\right)$, Santa Barbara $\left(34^{\circ} \mathrm{N}, 120^{\circ} \mathrm{W}\right)$, and Riverside $\left(34^{\circ} \mathrm{N}, 117^{\circ} \mathrm{W}\right)$. Red (blue) curves show traces for $1997 /$ 98 (2015/16), while the gray band shows the 1901-2015 daily climatology. This study focuses on the DJF (indicated by the blue shaded box) seasonal average conditions, during which the vast majority of water-year precipitation accumulates.

By late summer 2015, a major El Niño event was under way, and was expected to peak at "super El Niño" levels as per NOAA's "ENSO diagnostic discussion", (NOAA 2015), similar to the $1997 / 98$ event and with potentially similar impacts (Changnon 1999). That winter had been exceptionally wet in SCAL (Fig. 1, red lines), as were the rainy seasons of the previous two super Niño events of 1877/78 and 1982/83 (Kiladis and Diaz 1986), raising hopes that drought relief would be forthcoming. Those expectations were somewhat tempered by the fact that Ropelewski and Halpert (1986) had not found any general relationship between El
Niño and California rainfall in their historical analysis, whereas subsequent more detailed work by Schonher and Nicholson (1989) as well as Redmond and Koch (1991) showed good observational linkage between wet rainy seasons in SCAL and El Niño. Modeling studies by Kumar and Hoerling (1998) and more recently Hoell et al. (2016, and references therein) made the case that strong El Niño events had a more reliable wet impact on SCAL than weaker ones, thereby reconciling somewhat the various empirical analyses. In this context, the notion that the major El Niño of 2015/16 could potentially deliver strong impacts on SCAL was even touted in media reports claiming it was "too big to fail" [e.g., Lin (2015) in the Los Angeles Times]. Unfortunately, the observed rainfall totals in DecemberFebruary 2015/16 were underwhelming in Southern California (Fig. 1), adding yet another drought winter to the now 5-yr tally rather than bringing much anticipated relief.

What happened in 2016? In this study we address the 2016 boundary forcing impact on SCAL winter precipitation and specifically address the probability of occurrence for the observed dry conditions using a large ensemble of climate simulations. We diagnose Atmospheric Model Intercomparison Project (AMIP) experiments that span a historic period of 1979-2016. The robustness of our findings is tested by reproducing these experiments using three model suites.

We also ask why SCAL precipitation in 2016 was so much lower than in 1998. We especially address whether the observed very wet condition in 1998 served as a suitable analog to guide expectations for 2016. Was 1998 indeed a reasonable analog, and if not, why not?

The principal tool for answering these questions is the AMIP simulations from the NCEP Global Forecast System, version 2 (GFSv2), the atmospheric component of the NCEP Climate Forecast System, version 2 (CFSv2). In addition to determining the boundary forced signal and the internal variability relative to such signals during strong El Niño events and 2016 especially, we also compare the retrospective GFSv2 simulations to the dynamical seasonal predictions made by the coupled Climate Forecast System. Our paper is structured as follows: Section 2 describes both observational and model datasets used for this study. Section 3 organizes our results into observational comparisons between 1997/98 and 2015/16 (section 3a), suitability assessment of the main model used here (section $3 b$ ), probability estimates of the rareness of the 2015/16 precipitation in Southern California (section 3c), simulated atmospheric signals for both events in all three model suites (section $3 d$ ), and predictability assessment for $2015 / 16$ based on 
operational model output (section 3e). All of the above are summarized in section 4 , in addition to concluding remarks.

\section{Observed and model data}

The focus of this study is on December-February (DJF) precipitation in the North American Southwest, with particular emphasis on the land area within the rectangles shown in Fig. 2. The area, bounded by $32^{\circ}-$ $37^{\circ} \mathrm{N}, 125^{\circ}-115^{\circ} \mathrm{W}$, referred to hereafter as SCAL, is almost entirely within Southern California but extends slightly into Nevada and the Mexican state of Baja California.

The characteristics of observed precipitation over the study area are described from analysis of gauge-based gridded monthly Global Precipitation Climatology Centre (GPCC) datasets combined version (V7 for the period 1901 to 2013 and V4 monitoring dataset from 2014 onward; Schneider et al. 2014), available at $1^{\circ} \times 1^{\circ}$ resolution. To explore the possible drivers for SCAL precipitation, we have also presented a global view of SST and precipitation fields. The observed SST data, on a $1^{\circ} \times 1^{\circ}$ grid, are from Hurrell et al. (2008). Global precipitation fields are from the Climate Prediction Center (CPC) Merged Analysis of Precipitation (CMAP; Xie and Arkin 1997), available at a $2.5^{\circ} \times 2.5^{\circ}$ resolution. Observed upper-level circulation patterns are derived from analysis of $200-\mathrm{hPa}$ geopotential height fields using the National Centers for Environmental Prediction (NCEP)-National Center for Atmospheric Research (NCAR) reanalysis data (Kalnay et al. 1996).

To examine the sensitivity of SCAL precipitation to the global SST forcing during El Niño events, we primarily utilize a 50-member ensemble of atmospheric model simulations [available online at the Facility for Climate Assessments (FACTS) website; see https:// www.esrl.noaa.gov/psd/repository/alias/facts]. Referred to as AMIP experiments, the data we use are from the NCEP GFSv2 (Zhang et al. 2016). The GFSv2 model is the atmospheric component of the NCEP CFSv2 (Saha et al. 2014). The GFSv2 model has spectral T126 horizontal resolution with 64 vertical levels and is forced with specified observed monthly varying SSTs and sea ice (Hurrell et al. 2008) and carbon dioxide concentrations for 1979-2016. Climatological values are specified for other greenhouse gases (e.g., $\mathrm{CH}_{4}, \mathrm{NO}_{2}, \mathrm{O}_{3}$, and $\mathrm{CFCs}$ ), aerosols (including volcanic), and solar forcing.

In addition to the 50-member ensemble, a $200-\mathrm{yr}$ climatological run of GFSv2 without interannual variability in boundary conditions or external radiative forcing has been conducted using a repeating seasonal cycle of SSTs and fixed carbon dioxide concentrations.
The climatological run is used to isolate the role of internal atmospheric variability on wintertime California precipitation.

To assess robustness we have also created and analyzed both a 30-member ensemble of AMIP simulations from the European Centre for Medium-Range Weather Forecasts-Hamburg Max Planck Institute for Meteorology Model, version 5.4 (ECHAM5.4; Roeckner et al. 2003), and a 50-member ensemble of AMIP simulations from the NCAR Community Atmosphere Model (CAM5; Neale et al. 2012). The ECHAM5 model was run at spectral T159 $\left(\sim 0.75^{\circ} \times \sim 0.75^{\circ}\right)$ horizontal resolution with 31 vertical levels, and the CAM5 model was run at an $\sim 1^{\circ}$ horizontal resolution with 30 vertical levels. Specified SST and sea ice conditions used in the two models are the same, but the time-evolving external forcings are different. Both models are subjected to time-evolving greenhouse gas (GHG) and ozone variations, but only CAM5 also includes variations in anthropogenic and volcanic aerosols. For observations and AMIP simulations, anomalies are calculated relative to a 1981-2010 reference period.

To address the predictability of SCAL rainfall during 2015/16, we examined two ensembles of initialized coupled model forecasts of the NCEP CFSv2. One set, comprising 24 members, is referred to as the seasonal forecast, which is initialized in November (four times daily on 2, 7, 12, 17, 22, and 27 November) and predicts the subsequent December-February seasonal mean. The other set, comprising 16 members, is referred to as the monthly forecast, which is initialized monthly (four times daily on 12, 17, 22, and 27 November; 12, 17, 22, and 27 December; and 11, 16, 21, and 26 January) and predicts the subsequent months December, January, and February, respectively. We calculate the DJF means following the same procedure as described in Zhang et al. (2014). The anomalies of the CFSv2 forecasts are calculated based on the 30-yr-long (1982/83 through 2011/12) reference period that spans the reforecast archive. The monthly forecast set will provide an estimate of the effect of updated initializations of atmospheric conditions relative to seasonal forecasts.

\section{Results}

\section{a. Observed SCAL precipitation and global context}

Southern portions of California, Nevada, and Arizona were anomalously dry during winter 2016, in stark contrast to much above normal precipitation that occurred over the same region during winter 1998 (Fig. 2, left). For the SCAL region outlined in Fig. 2, the magnitude of rainfall differences between these strong El Niño events 
Precipitation anomalies

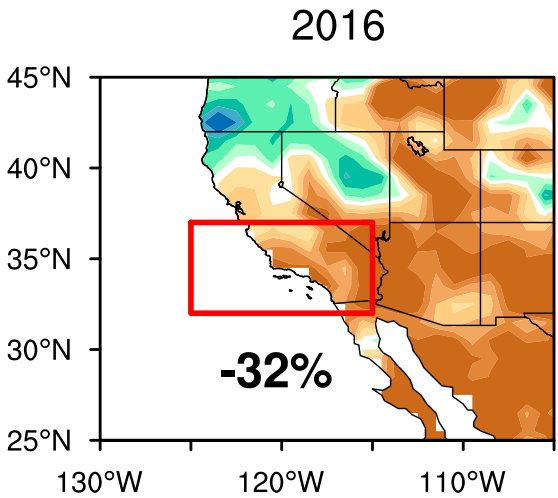

1998

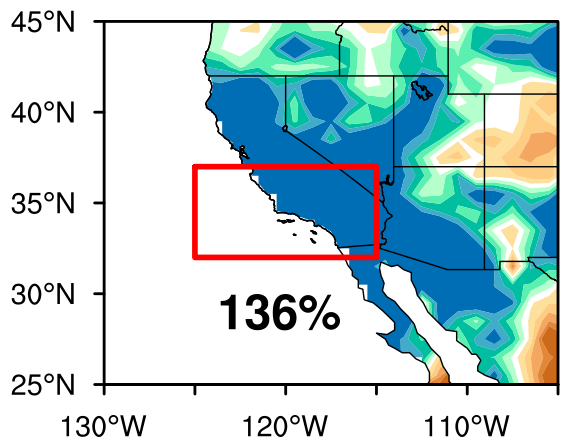

$2016-1998$

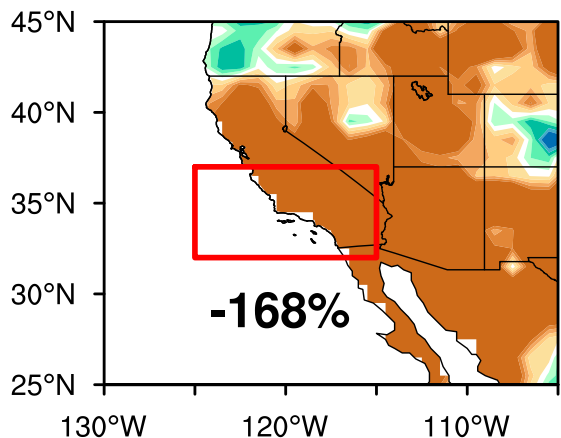

(\%)

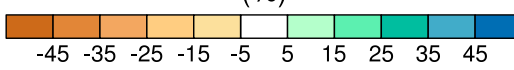

Z200/SST anomalies

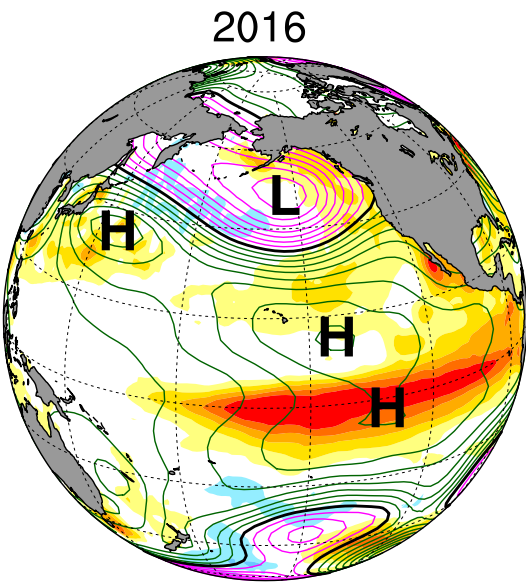

1998

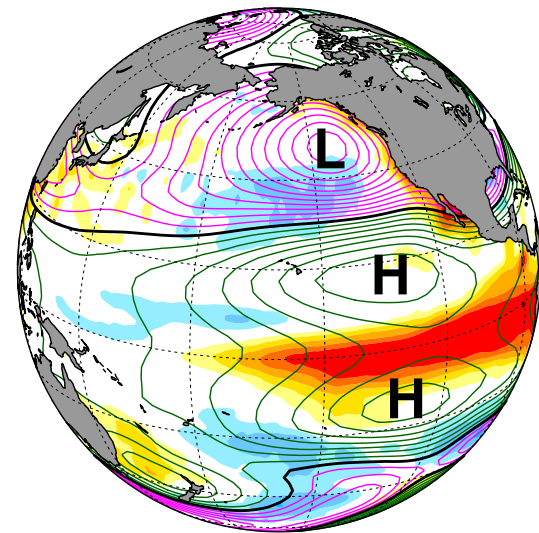

2016 - 1998

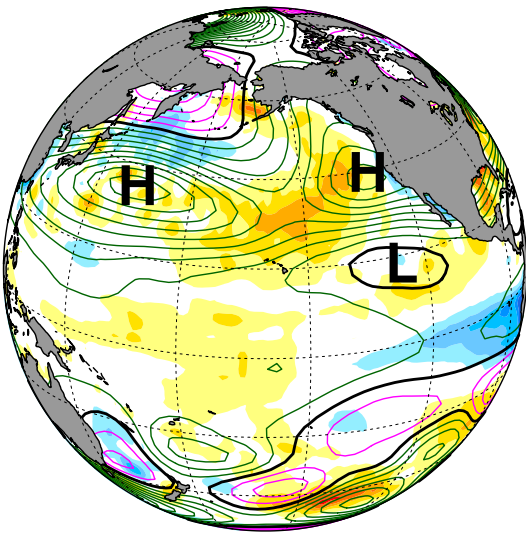

$\left({ }^{\circ} \mathrm{C}\right)$

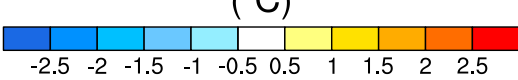

FIG. 2. Observed DJF (left) precipitation anomalies (\% departures) and (right) 200-hPa height anomalies (contour) overlaid with SST anomalies (shaded) for (top) 2015/16 and (middle) 1997/98 and (bottom) the difference. The period of reference is 1981-2010. Plotted values are percent departures for the SCAL land area bounded by $32^{\circ}-37^{\circ} \mathrm{N}, 125^{\circ}-115^{\circ} \mathrm{W}$. The contour interval is $15 \mathrm{~m}$; green (magenta) contours are positive (negative). 

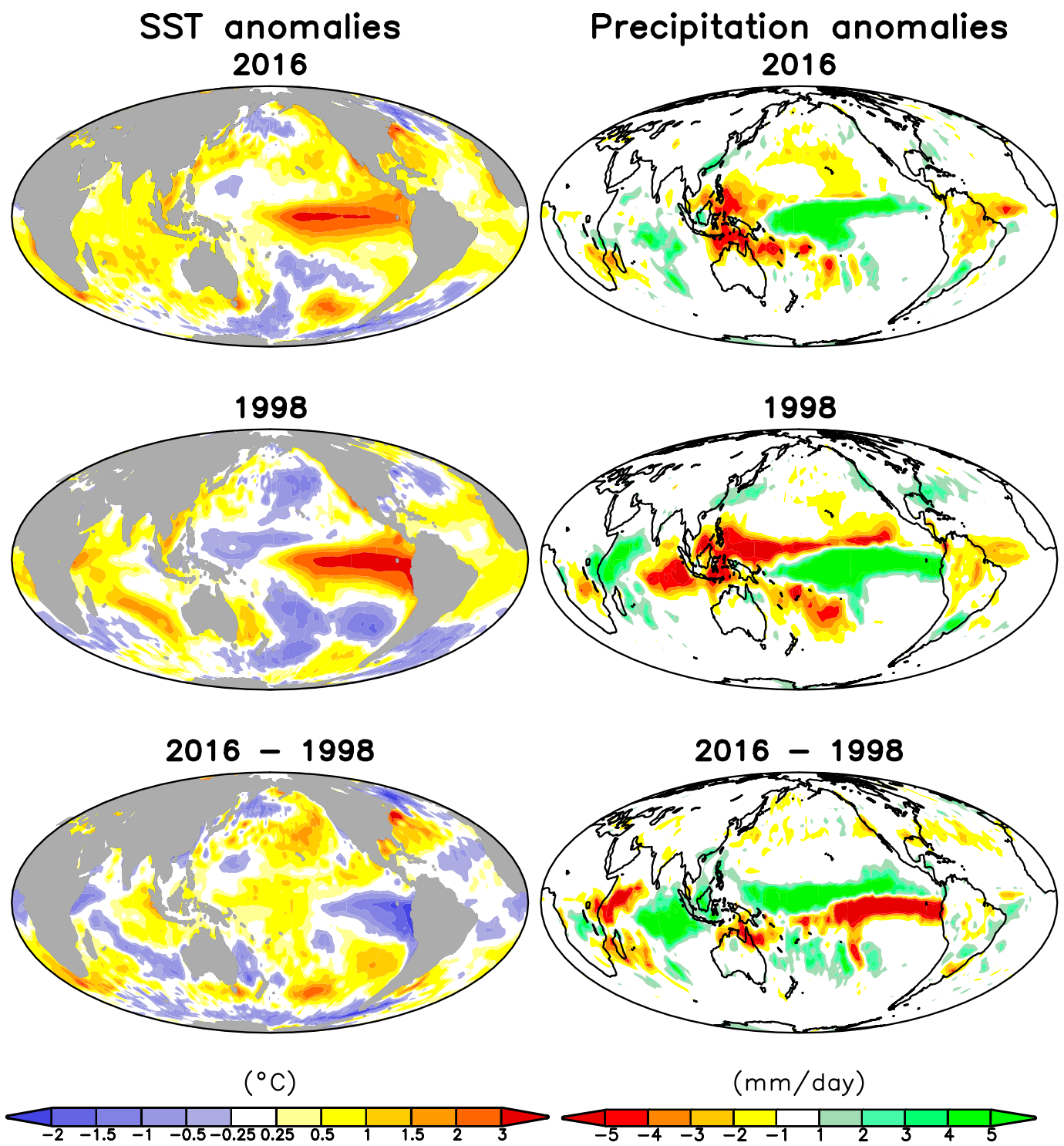

FIG. 3. Observed DJF (left) SST anomalies $\left({ }^{\circ} \mathrm{C}\right.$ ) and (right) precipitation anomalies (mm day ${ }^{-1}$ ) for (top) 2015/16 and (middle) 1997/98 and (bottom) the difference. Reference period is 1981-2010.

equaled $168 \%$ of the climatological winter normal (Fig. 2, bottom left).

A less effective atmospheric circulation pattern for delivering moisture-bearing storms to SCAL was the immediate cause for the drier 2016 conditions. Shown in Fig. 2 (right) are 200-hPa height anomalies for the two winters highlighting the Pacific sector. The classic El Niño-related teleconnection pattern (e.g., Horel and Wallace 1981) is evident during both years consisting of tropical twin anticyclones and a deepened Aleutian low, although the latter feature is shifted farther north into the Gulf of Alaska during 2016. The difference map (Fig. 2, bottom right) shows the comparatively higher 200-hPa heights across virtually the entire North Pacific having maximum values between $30^{\circ}$ and $40^{\circ} \mathrm{N}$ indicative of a northward displaced storm track in 2016 compared to 1998. As a consequence, the frequency of rainy days was much reduced in 2016, as is evident from the daily rainfall time series at Santa Barbara and Riverside, California (see Fig. 1).

This paper's central question is whether the striking contrast in SCAL precipitation between these two strong El Niño events was potentially predictable, assuming that differences in their SSTs had been accurately forecast. Figure 3 (left) shows the observed global wintertime SST anomalies for 2016 (top) and 1998 (middle) and their difference (bottom). The globally averaged SSTs were $0.18^{\circ} \mathrm{C}$ warmer in 2016 winter 
TABLE 1. DJF El Niño indices for 2015/16 compared to 1997/98. All indices are based on a 1981-2010 climatological reference period.

\begin{tabular}{ccccc}
\hline \hline \multirow{2}{*}{$\begin{array}{c}\text { El Niño } \\
\text { events }\end{array}$} & Niño-4 & Niño-3.4 & Niño-3 & Niño-1+2 \\
\cline { 2 - 5 } & 0.8 & 2.4 & 3.1 & 3.6 \\
$1997 / 98$ & 1.5 & 2.6 & 2.5 & 1.4 \\
\hline
\end{tabular}

compared to 1998, although with distinct regional structures. For instance, the SST difference over the Indian Ocean consists of a zonal dipole pattern resembling the well-known dipole mode that prevailed during 1998 (Saji et al. 1999) but was absent in 2016. The tropical Pacific SST difference reflects a zonal pattern that is mostly due to different El Niño flavors in 2016 versus 1998: a stronger warming of the central basin and a weaker warming of the far eastern Pacific in 2016 is indicative of a more central Pacific (CP) than an eastern Pacific (EP) event (e.g., Wang and Weisberg 2000; Kug et al. 2009).

Table 1 compares various El Niño SST indices during 2016 and 1998 winters. The widely used Niño-3.4 region for monitoring El Niño indicates very similar SST departures for the two cases, of approximately $2.5^{\circ} \mathrm{C}$. The principal difference is that Niño-4 warming was nearly twice as great in 2016, whereas Niño-1+2 warming was less than half. In this sense the 2016 event was not a pure EP type but a mixture of EP and CP El Niño flavors (see Paek et al. 2017).

These tropical SST differences were linked with and, as will be subsequently demonstrated, were largely responsible for the major differences in tropical rainfall patterns between the two El Niño winters. Satellite estimates of precipitation anomalies for each winter (Fig. 3, right) show a pronounced increase in rainfall over the equatorial central to eastern Pacific during 2016 and 1998, a robust signature of well-known El Niñorelated SST effects on the atmosphere. Drier than normal conditions prevailed over the far western Pacific during both winters.

Differences in tropical rainfall between these two winters are prominent, being comparable in their intensity and spatial extent to the separate seasonal anomalies during each El Niño (Fig. 3, bottom right). A $5^{\circ}-10^{\circ}$ poleward shift of enhanced ITCZ convection occurred during 2016 relative to 1998, spanning the entire El Niño monitoring region from $160^{\circ} \mathrm{E}$ to $90^{\circ} \mathrm{W}$. This displacement farther into the Northern Hemisphere is related to warmer SSTs within $0^{\circ}-20^{\circ} \mathrm{N}$ across the central and eastern Pacific during 2016. In addition to this meridional shift in rainfall patterns, there is also a zonal shift—-the center of strongest positive rainfall anomalies

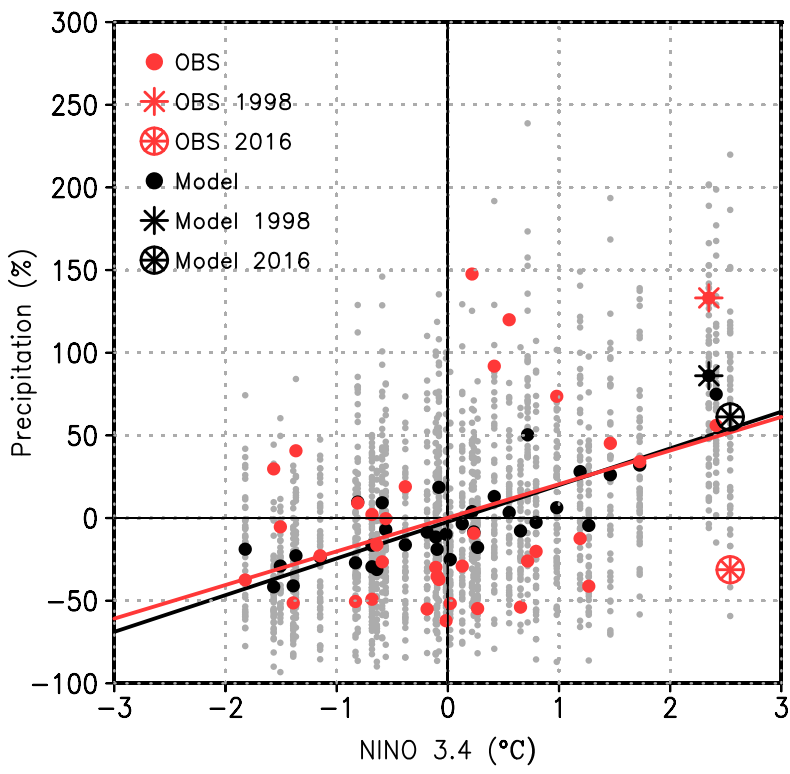

FIG. 4. Scatterplot of SCAL precipitation anomalies (\%, $y$ axis) vs Niño-3.4 $\left(5^{\circ} \mathrm{N}-5^{\circ} \mathrm{S}, 170^{\circ}-120^{\circ} \mathrm{W}\right)$ SST anomalies $\left({ }^{\circ} \mathrm{C}, x\right.$ axis $)$ during DJF. Red (black) dots display observations (GFSv2 ensemble mean). Gray dots display each of the 50-member ensemble GFSv2 simulations subjected to global SST forcing. Red (black) line is the regression relationship for observations (GFSv2 ensemble mean) with an $R^{2}$ value of $0.14(0.66)$. The mean regression relationship averaged over 50 -sample regression lines between individual model members and Niño-3.4 SST index has an $R^{2}$ value of 0.21 . The period of analysis is 1979-2016, although regression analysis only covers $1979-2015$. The $2015 / 16$ and $1997 / 98$ values highlighted with asterisks inside circles and asterisks alone, respectively. Precipitation is averaged over $32^{\circ}-37^{\circ} \mathrm{N}, 125^{\circ}-115^{\circ} \mathrm{W}$.

in 2016 is located approximately $20^{\circ}$ longitude west of that in 1998. The resulting zonal dipole pattern in precipitation is well aligned with the dipole structure of tropical Pacific SST differences (cf. Fig. 3, bottom panels) and resembles a fingerprint of tropical Pacific rainfall sensitivity to stronger warming of the central compared to eastern Pacific (e.g., Zhang et al. 2016). Finally, a large difference in Indian Ocean rainfall mainly reflects the strong anomaly pattern present in 1998 that was linked with the aforementioned positive Indian Ocean dipole mode.

\section{b. Model suitability assessment}

We assess GFSv2 suitability as a tool for diagnosing causes of 2016 SCAL dryness by quantifying the realism of its historical SCAL rainfall-ENSO linkage and also by evaluating the model's ability to predict SCAL winter precipitation variability. Subsequently, we will compare GFSv2 simulations of the 2016 winter with those generated by two other models in order to address structural model uncertainty. Figure 4 shows observed winter SCAL precipitation anomalies (percent of average) for 
37 individual years during 1979-2016 (red dots) plotted as a function of the wintertime Niño-3.4 index. The observed linear correlation for $1979-2015$ is $0.38,{ }^{1}$ and the linear regression relation is shown by the solid red line. The GFSv2 ensemble-mean simulated SCAL precipitation anomalies are also plotted for each winter (black dots), and they correlate with observed SCAL precipitation at 0.47 (see footnote). The linear regression between the GFSv2 ensemble-mean precipitation and Niño-3.4 SSTs, shown by the solid black line, is statistically indistinguishable from the observed relation. The regression relationships between SCAL rainfall and each of the standard Niño (Niño-4, Niño-3.4, Niño-3, and Niño-1+2) indices are similar (not shown).

The results in Fig. 4 establish that the GFSv2 has significant skill in simulating the historical variability in SCAL winter precipitation. Related to that capability, it exhibits realistic SCAL rainfall sensitivity to ENSO driving by reproducing the observed tendency for winters to be approximately $20 \%$ wetter than normal for a $1^{\circ} \mathrm{C}$ Niño-3.4 warm SST anomaly. It is thus not altogether surprising that the GFSv2 ensemble mean was skillful in simulating the observed very wet winters during the prior two strongest El Niño events. These inclinations are not deterministic, however, as indicated by the considerable scatter in simulated SCAL rainfall for identically strong El Niño forcing, a feature of the SCAL-El Niño linkage to be discussed further below.

An additional inquiry of this paper, one tied intimately to the predictability question, is why the GFSv2 ensemble mean (and the official seasonal forecast) was not skillful for SCAL winter precipitation during the strong 2016 El Niño. To be sure, the GFSv2 ensemblemean 2016 precipitation (black asterisk inside circle in Fig. 4) is closely aligned with both its own and observed linear ENSO relationships in 2016. By contrast, the observed 2016 SCAL precipitation (red asterisk inside circle in Fig. 4) departs greatly from its ENSO regression relationship in a dry sense. Note also that the observed 1998 SCAL precipitation (red asterisk in Fig. 4) departed greatly from its ENSO regression relationship, although in a wet sense. In both cases the observations fall within the model spread (gray dots); in fact, the observations fall within the model spread for virtually all of the 37 winters since 1979. As such, the large difference between 2016 observed SCAL rainfall and the GFSv2 ensemble mean is not necessarily due to model deficiency,

\footnotetext{
${ }^{1}$ A univariate Student's $t$ test assuming 35 degrees of freedom indicates that correlations of 0.38 and 0.47 are significantly different from zero at $95 \%$ and $99 \%$ confidence levels, respectively.
}

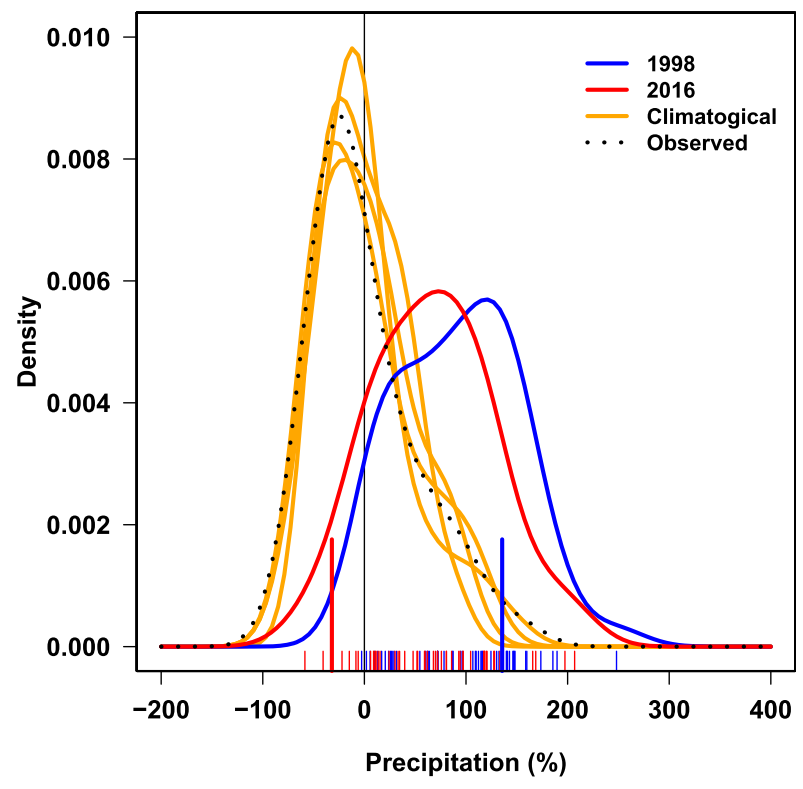

FIG. 5. PDFs of SCAL precipitation (\% departure) for DJF 2016 (red curve), 1998 (blue curve), and control simulations (orange curves). El Niño case results are based on 50-member ensemble GFSv2 simulations subjected to global SST forcing. Control integrations based on four separate 50-yr samples of GFSv2 simulations subjected to climatological 1981-2010 SSTs. Observed density function for a 47-yr sample of ENSO-neutral years shown by a dashed curve. The tick chart across the bottom shows model individual samples for the 2015/16 (red) and 1997/98 (blue) simulations, and large tick marks show observed 2015/16 (red) and 1997/ 98 (blue) departures. The PDFs are nonparametric curves utilizing kernel density estimation with a Gaussian smoother.

one that would render it unsuitable for evaluating causes of the failed 2016 rains. Indeed, we will capitalize on the GFSv2 large ensemble sizes and the considerable spread (even during strong El Niño winters) to estimate extreme event probabilities and thereby further characterize the observed 2016 SCAL dryness.

\section{c. Probability estimates for failed SCAL rains during 2016}

Figure 5 shows probability density functions (PDFs; shown as nonparametric fits to the histograms of the raw data) of SCAL winter precipitation based on observations and three different GFSv2 experiments. It is instructive to first examine the statistics of unforced variability. These are derived from control experiments subjected only to the repeating climatological seasonal cycle having, in particular, no interannual ENSO variability. Each of the four orange PDFs, drawn from independent $50-\mathrm{yr}$ control integrations, is statistically indistinguishable from an observed PDF drawn from 47 years of historical ENSO-neutral winters (dotted curve). The result indicates that in the absence of ENSO 
variability the most frequent SCAL winter precipitation condition is one of dryness, with a statistical mode of $-21 \%$ in the control runs and $-24 \%$ in observations.

We next plot in Fig. 5 the frequency distributions from the two forced experiments using the 50 -member ensemble GFSv2 AMIP experiments of 1998 (blue curve) and 2016 (red curve). Short tick marks on the abscissa indicate individual samples, while long tick marks indicate the corresponding observed values for the two winters. The statistics of SCAL rainfall summarized by these forced PDFs are significantly different from those summarized by the unforced PDFs. Noteworthy is that the most frequent SCAL winter precipitation condition is one of wetness in the presence of strong El Niño driving, with a statistical mode of $+121 \%$ in the 1998 runs and $+73 \%$ in 2016 runs. The PDFs of SCAL precipitation are also significantly different between the 1998 and 2016 experiments. In particular, comparison of these two distributions reveals a greater likelihood for drier (wetter) SCAL outcomes when forced with 2016 (1998) global boundary conditions. As shown in appendix A (Fig. A1), the probability of exceeding the observed 2016 dryness was $4.8 \%$ under 2016 forcing compared to $1.6 \%$ under 1998 forcing, or 3 times as high. This compares with $24 \%$ odds of exceeding the observed 2016 dryness in the climatological control run (Fig. A1). Likewise, the odds of exceeding the observed 1998 SCAL wetness in our GFSv2 experiments was about half under the influence of 2016 forcing compared to 1998 forcing $(11 \%$ vs $21 \%$, compared to $0.1 \%$ in the control run).

There are three main points to take away from Fig. 5 . First, the observed SCAL 2016 dryness was almost certainly an articulation of unusual-though not unprecedentedunforced variability. This conclusion is inferred from the fact that the observed condition resides in the dry tail of the forced PDF (red curve), with only two of the GFSv2 50 -member ensemble simulations for 2016 being as dry as observed. These are low probability occurrences in 2016 GFSv2 runs resulting purely from the effects of strong internal variability (unforced by the SST boundary states) in the model. While the observed internal variability in the presence of 2016 SST forcings is not known, we have established two attributes of the model that support our interpretation. We demonstrate the realism of the model's internal variability in the absence of ENSO forcing (see Fig. 5). We have also established the realism of its overall ENSO sensitivity (see Fig. 4). Our argument is thus supported by the fact that the model and observations have comparable statistics of unforced and forced variability.

Second, the effect of strong El Niño-related boundary forcing, during either 2016 or 1998, greatly reduced the likelihood for such a dry SCAL outcome compared to its likelihood under climatological forcing. Third, the particular global forcing operating during the 2016 El Niño increased the risk for an extreme failure of SCAL winter rains compared to the influence of global forcing operating during the $1998 \mathrm{El} \mathrm{Niño.} \mathrm{This} \mathrm{latter} \mathrm{point} \mathrm{is} \mathrm{the} \mathrm{key}$ result insofar as the perception of the efficacy of strong El Niño driving of SCAL rainfall was in no small part bound to the experience of flooding rains during 1998. Yet, here we show that despite nearly identical Niño-3.4 SST anomalies, the forced signals were sufficiently different such that 1998 was far from being an exact analog for 2016 as concerns the risks for either extreme dry or wet SCAL winter rainfall.

\section{d. Simulated atmosphere signals for 2016}

Figure 6 shows the GFSv2 ensemble-mean winter anomalies for western U.S. precipitation (left) and $\mathrm{Pa}$ cific basin 200-hPa heights (right). The forced signal is wetness across the entire southwestern United States for both 2016 (Fig. 6, top) and 1998 (Fig. 6, middle). This is a consequence of anomalous low pressure situated in close proximity to the U.S. West Coast. For the Pacific basin as a whole, the atmospheric circulation signal broadly agrees with the observed circulation anomalies (cf. Figs. 2 and 6) and bears close resemblance to the well-known canonical El Niño teleconnection (e.g., Horel and Wallace 1981). The model's circulation patterns, however, are not identical for the two winters (as also noted for observations in section 3a): a more intense and farther eastward positioned Pacific low pressure anomaly occurs in 1998 compared to 2016. As a result, the magnitude of the GFSv2 wet signal in SCAL is less in 2016. In particular, the difference in the GFSv2 ensemble-mean signal of SCAL rainfall is $-25 \%$, a relative dryness that is consistent with other statistical measures described in section $3 \mathrm{c}$, including a lower median and mode and a greater likelihood for an extreme dry tail event.

We find this signal of relative SCAL dryness in 2016 (compared to 1998) to be robust to model uncertainty. Appendix B presents analysis of large ensemble simulations using two additional atmospheric models. Both of those indicate a wet signal over the western United States during the two winters; as in GFSv2, their wet signal is weaker in 2016. The greatest difference between 2016 and 1998 forced U.S. precipitation signals occurs over the North American Southwest including SCAL where the area-averaged 2016 precipitation signal ranges from $21 \%$ to $33 \%$ drier in the three models examined herein (Fig. B1).

The results support a high confidence that global boundary forcing during the 2016 strong El Niño was 
Precipitation anomalies

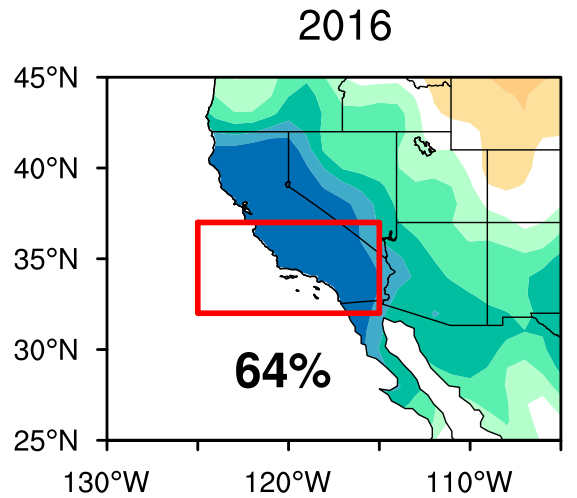

1998

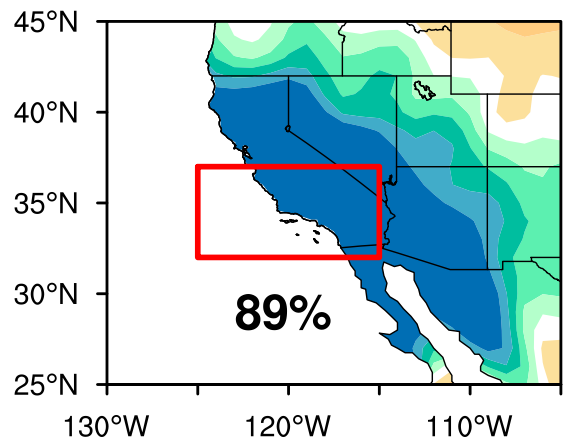

$2016-1998$

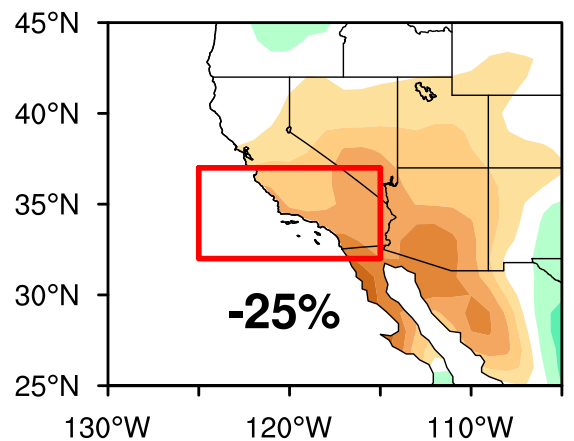

(\%)

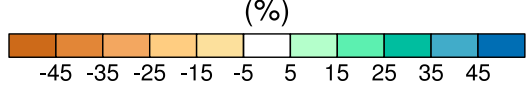

Z200/SST anomalies

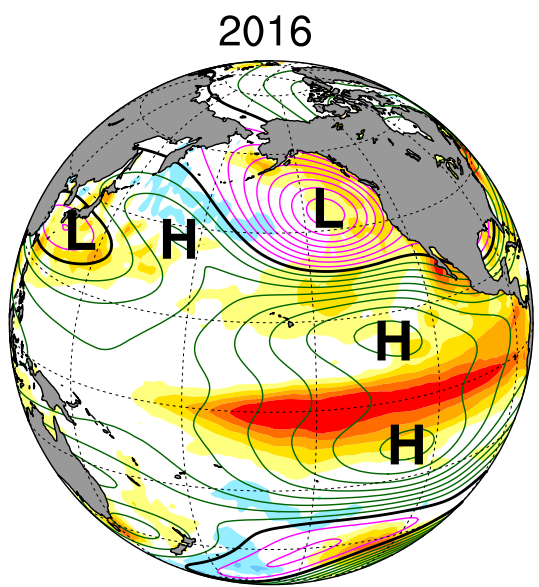

1998

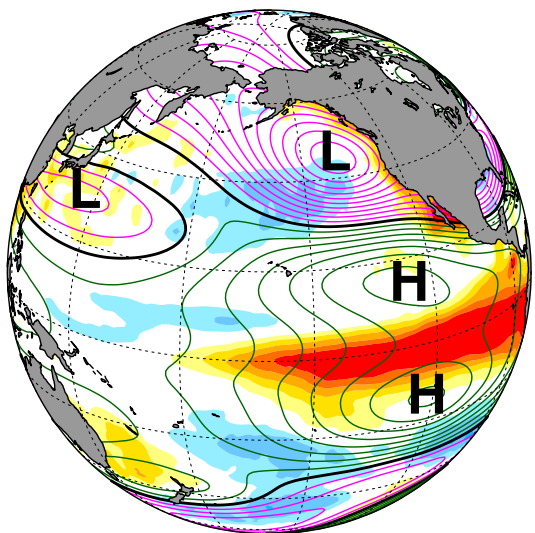

2016 - 1998

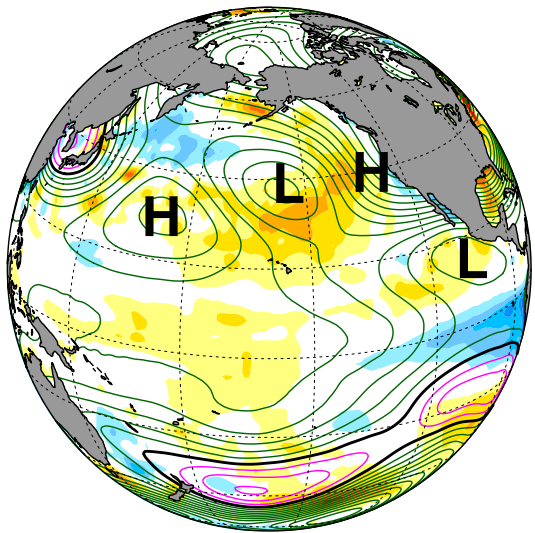

$\left({ }^{\circ} \mathrm{C}\right)$

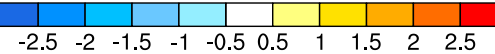

FIG. 6. GFSv2 simulated 50-member ensemble-mean DJF (left) precipitation anomalies (\% departures) and (right) 200-hPa height anomalies (contour) overlaid with observed SST anomalies (shaded) for (top) 2015/16 and (middle) 1997/98 and (bottom) the difference. Period of reference is 1981-2010. Plotted values are percent departures for the SCAL land area bounded by $32^{\circ}-37^{\circ} \mathrm{N}$, $125^{\circ}-115^{\circ} \mathrm{W}$. The contour interval is $15 \mathrm{~m}$ for (top) and (middle) and $5 \mathrm{~m}$ for (bottom); contour colors same as Fig. 2. 
less effective in driving SCAL wetness than the global forcing operating in 1998. It is thus meaningful to probe whether more specific predictive understanding can be gleaned from these AMIP simulations. For instance, was the drier 2016 signal an indication of SCAL sensitivity to the flavor of El Niño? Using satellite rainfall estimates, we contrasted the tropical Pacific rainfall between 2016 and 1998 in section 3a, finding substantial deviations in the intensity and spatial extent of anomalies. The GFSv2 AMIP simulations affirm that those were indeed mostly due to the atmosphere's response to SST forcing, as supported by results in Fig. 7 which show ensemble-mean rainfall anomalies for 2016 (top) and 1998 (middle) and their difference (bottom). Prior model experimentation by Barsugli and Sardeshmukh (2002) demonstrated that winter precipitation over the North American Southwest could be particularly sensitive to forcing from the Niño-4 relative to Niño-3 region. As such, an SST-driven westward shift of convection toward the date line in 2016 relative to 1998 may have been key to harvesting U.S. predictability. However, a stronger sensitivity to date line forcing implies a wetter and not a drier signal. Indeed, more recent model studies of U.S. precipitation sensitivity to flavors of El Niño find that stronger warming in the central versus eastern equatorial Pacific leads to a wetter signal over SCAL (e.g., Zhang et al. 2016). As such, an explanation for the drier SCAL signal in our AMIP experiments must look outside the El Niño regions, since details of the El Niño-related SST pattern that distinguished the 2016 and 1998 events were unlikely the cause.

As another candidate, the results of Fig. 7 affirm that differences in Indian Ocean convection were also SST forced, and that such rainfall may have been predictable if the Indian Ocean SST dipole mode was predicted. Could this overall Indo-Pacific SST forcing pattern therefore have been responsible for the drier SCAL signal in 2016? A satisfactory answer based solely on the AMIP simulations cannot be offered. In particular, the presence of mostly enhanced Indian Ocean precipitation in 2016 relative to 1998 , together with enhanced central Pacific convection, complicates interpretation of the impacts on SCAL rainfall. This is because of a nodal sensitivity of atmospheric teleconnections; likesigned forcing in the tropical Indian and the central Pacific Oceans yield opposite-signed effects on the Pacific-North American circulation pattern (e.g., Simmons et al. 1983; Barsugli and Sardeshmukh 2002). Additional model experiments, beyond the scope of this paper, are thus needed to determine which boundary forcings distinguishing 2016 from 1998 were most important for predicting a drier 2016 SCAL rainy season.

\section{GFSv2 precipitation anomalies}
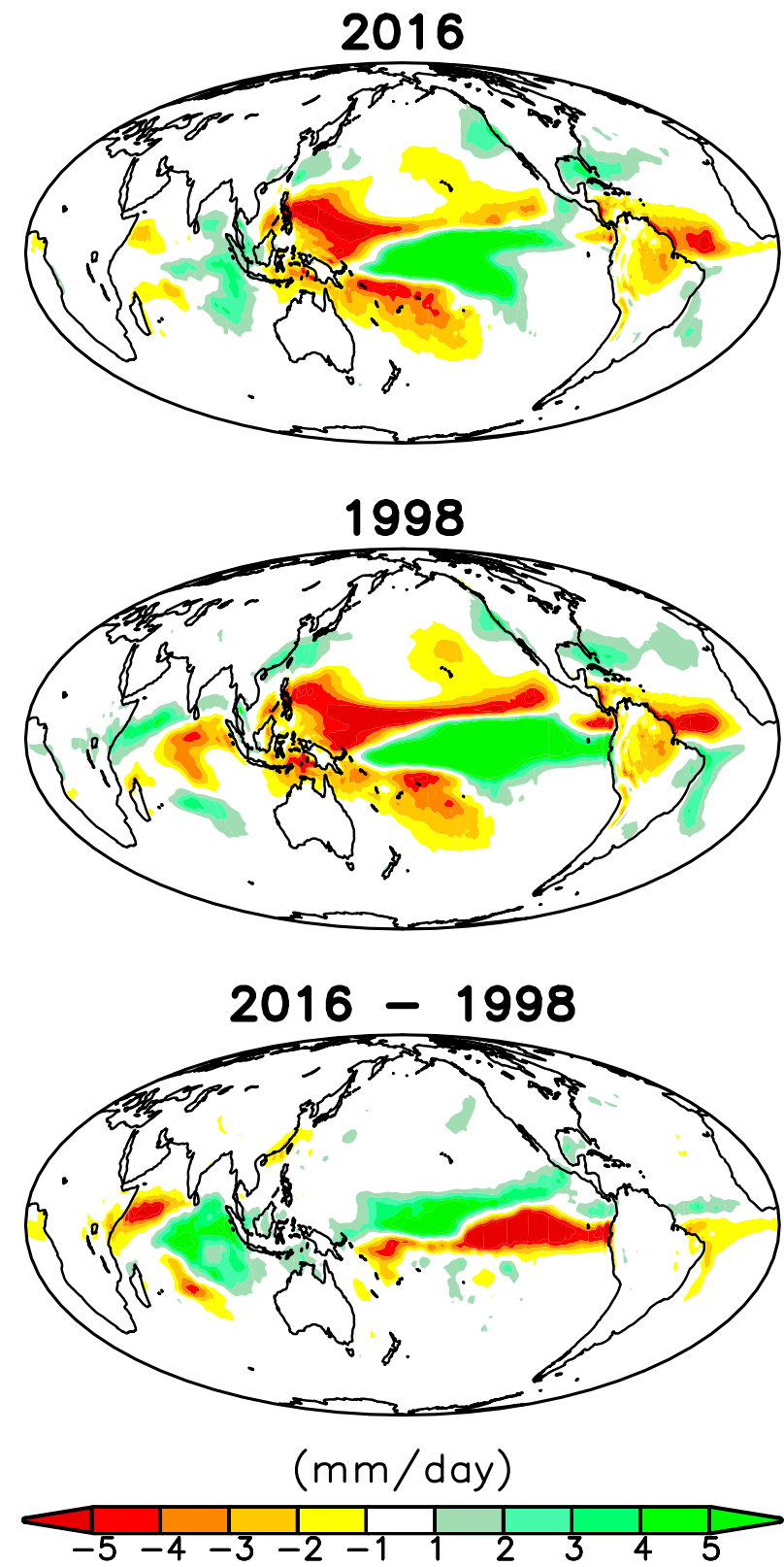

FIG. 7. DJF precipitation anomalies $\left(\mathrm{mm} \mathrm{day}^{-1}\right)$ from GFSv2 AMIP simulations for (top) 2015/16 and (middle) 1997/98 and (bottom) the difference. Model results are based on a 50-member ensemble. Reference period is 1981-2010.

\section{e. Predicted ocean-atmosphere signals for 2016}

Two ensembles of initialized coupled model forecasts are examined using the NCEP CFSv2, the atmospheric component of which is the GFSv2 whose uninitialized simulations were diagnosed above. One set, referred to herein as the seasonal forecast, is 
initialized in November for which the subsequent December-February seasonal mean predictions are examined. The other set, referred to herein as the monthly forecast, is initialized each month (November, December, and January) for which the subsequent monthly mean prediction was generated. We examine the average of these sequential monthly forecasts and calculate their December-February means.

Figure 8 shows the CFSv2 seasonal (left) and CFSv2 monthly (right) predictions of DJF precipitation anomalies for 2016 (top) and 1998 (middle) and their differences (bottom). The ensemble-mean seasonal forecast is wet over the North American Southwest during both winters, with the largest signal over SCAL. However, the seasonal prediction is considerably drier for 2016 than for 1998 for SCAL in particular, mimicking results from the AMIP experiments. The close agreement between the CFSv2 predictions and AMIP simulations is not entirely surprising since at such short lead times the 1998 and 2016 SST anomalies are realistically predicted (left panels of Fig. 9 vs Fig. 3), consistent with an overall high skill in 1-month lead Niño-3.4 winter SST predictions (Saha et al. 2014). Considerable skill in predicting the tropical rainfall anomalies for the two winters largely follows from the SST forecast skill in light of the strong coupling between ocean and atmosphere in the tropics on seasonal time scales (cf. Fig. 9 and Fig. 3). Notwithstanding these encouraging suggestions for prediction capabilities, the 2016 SCAL wet signals (i.e., ensemble means) occurring in both the CFSv2 seasonal forecasts and the GFSv2 retrospective climate simulations were diametrically opposed to the dry conditions actually observed.

Our interpretation for the observed dryness is that it was most probably due to subseasonal variabilitya possible example of which is discussed in section 4but whose activity was likely unconstrained by the 2016 global boundary forcing. We previously alluded to the intensity of internal variability when highlighting the considerable spread of GFSv2 simulations even for situations of strong El Niño boundary forcing (see Figs. 4 and 5). Likewise, the initialized coupled forecasts provide strong support for the presence of considerable coupled internal variability, and indicate that the dry 2016 winter could not have been skillfully foreseen from simply knowing initial conditions (atmosphere, ocean, and land) in November 2015. This point was already noted based on CFSv2 ensemble seasonal forecasts for 2016 and 1998, and is evident from the large scatter among individual forecast members (see Fig. 11 and subsequent discussions in section 4). Also, we examined a multimodel set of seasonal predictions generated by the so-called 12 global producing centers
(GPCs) (Graham et al. 2011). Figure 10 shows the ensemble-mean probabilistic DJF 2015/16 North American precipitation predictions based on November 2015 initialization from these centers. The multimodel results lead to an expectation that SCAL rains would most likely have been above normal precipitation, having about $50 \%$ probability of residing in the upper tercile.

The role of subseasonal variability can be further demonstrated by contrasting monthly and seasonal coupled model forecasts. Figure 8 (right) indeed provides evidence that monthly forecasts alone could have provided skillful incremental guidance. These monthly predictions, aggregated to form seasonal averages, reveal a much more dramatic difference in SCAL rainfall between the two winters, being near-normal for 2016 but $+165 \%$ above normal for 1998 . The contrast with the CFSv2 seasonal forecast and the AMIP experiments is striking. The improved prediction for both winters is apparently not linked to improvements in the SST predictions, which are largely indistinguishable between the seasonal (Fig. 9) and monthly (not shown) forecasts. Rather, the improvement is most likely the result of updated initializations of atmospheric conditions during the course of the winter that carried critical information of the particular drought-producing weather regime. A more detailed analysis of all predictability sources would be required to confirm this argument, but the results of these monthly forecasts support the view formulated from the ensemble AMIP experiments that internal atmospheric noise, rather than a boundary-forced signal, was principally responsible for the failed SCAL rains in 2016.

\section{Summary and concluding remarks}

Heightened expectations for copious California rains during the 2016 strong El Niño were fueled by lessons drawn from flooding rains that ravaged the state during the 1983 and 1998 strong El Niño events and from both empirical and model forecast guidance. Clearly, the predicted rains failed to materialize over Southern California, with seasonal precipitation totals being instead $32 \%$ below normal. This study sought to explain the failed SCAL rains of 2016, and to that end assessed the predictability and predictions for the region's 2016 winter climate. A principal finding is that 2016 SCAL dryness was not predictable from knowledge of global boundary forcing alone. The ensemble-mean responses in climate simulations using three different atmospheric models and from a multimodel average of coupled ocean-atmosphere forecasts initialized in November 2015 all produced a wet SCAL precipitation signal during December-February 2016. 
Seasonal forecast

2016

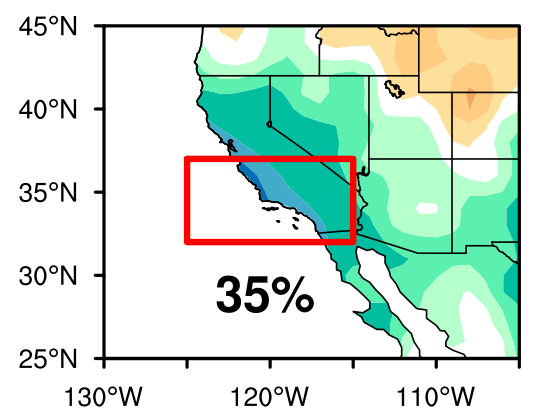

1998

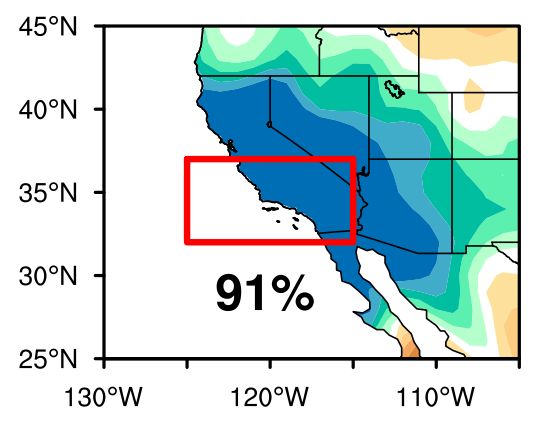

$2016-1998$

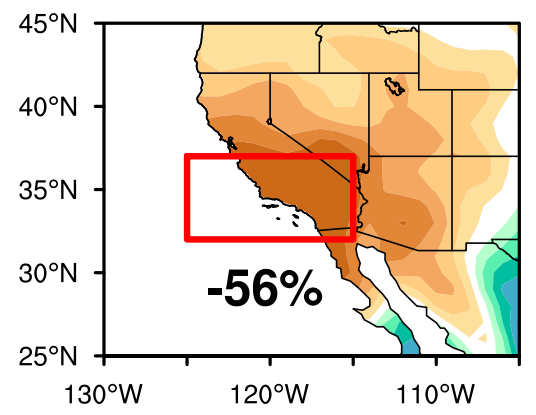

Monthly forecast

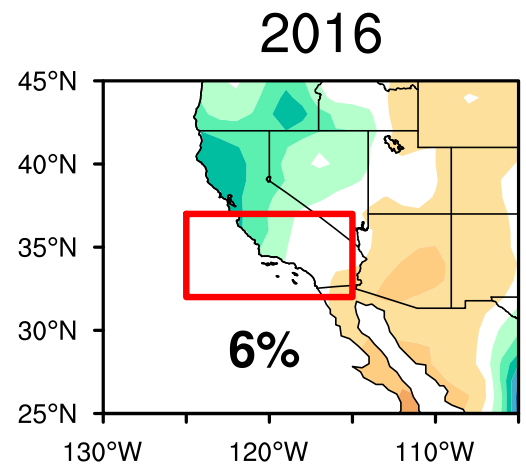

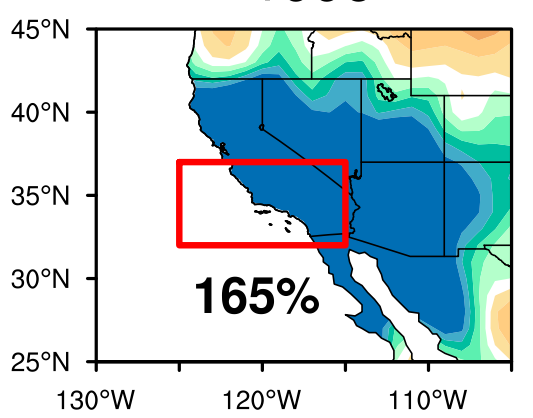

$2016-1998$

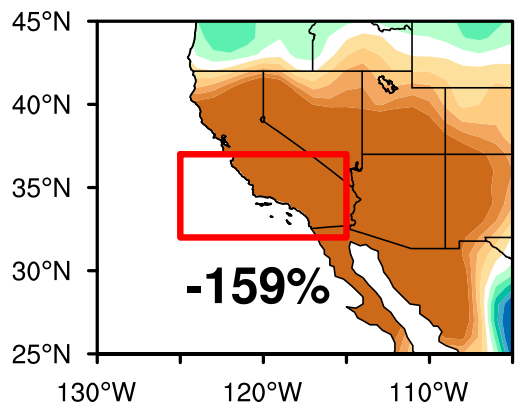

$(\%)$

FIG. 8. DJF precipitation anomalies (\% departures) from the (left) CFSv2 seasonal forecast and (right) CFSv2 monthly forecast for (top) 2015/16 and (middle) 1997/98 and (bottom) the difference. Results are based on a 24-member ensemble for seasonal forecast and a 16-member ensemble for monthly forecast. Reference period is 1982/83 through 2011/12. Plotted values are percent departures for the SCAL land area bounded by $32^{\circ}-37^{\circ} \mathrm{N}, 125^{\circ}-115^{\circ} \mathrm{W}$. 

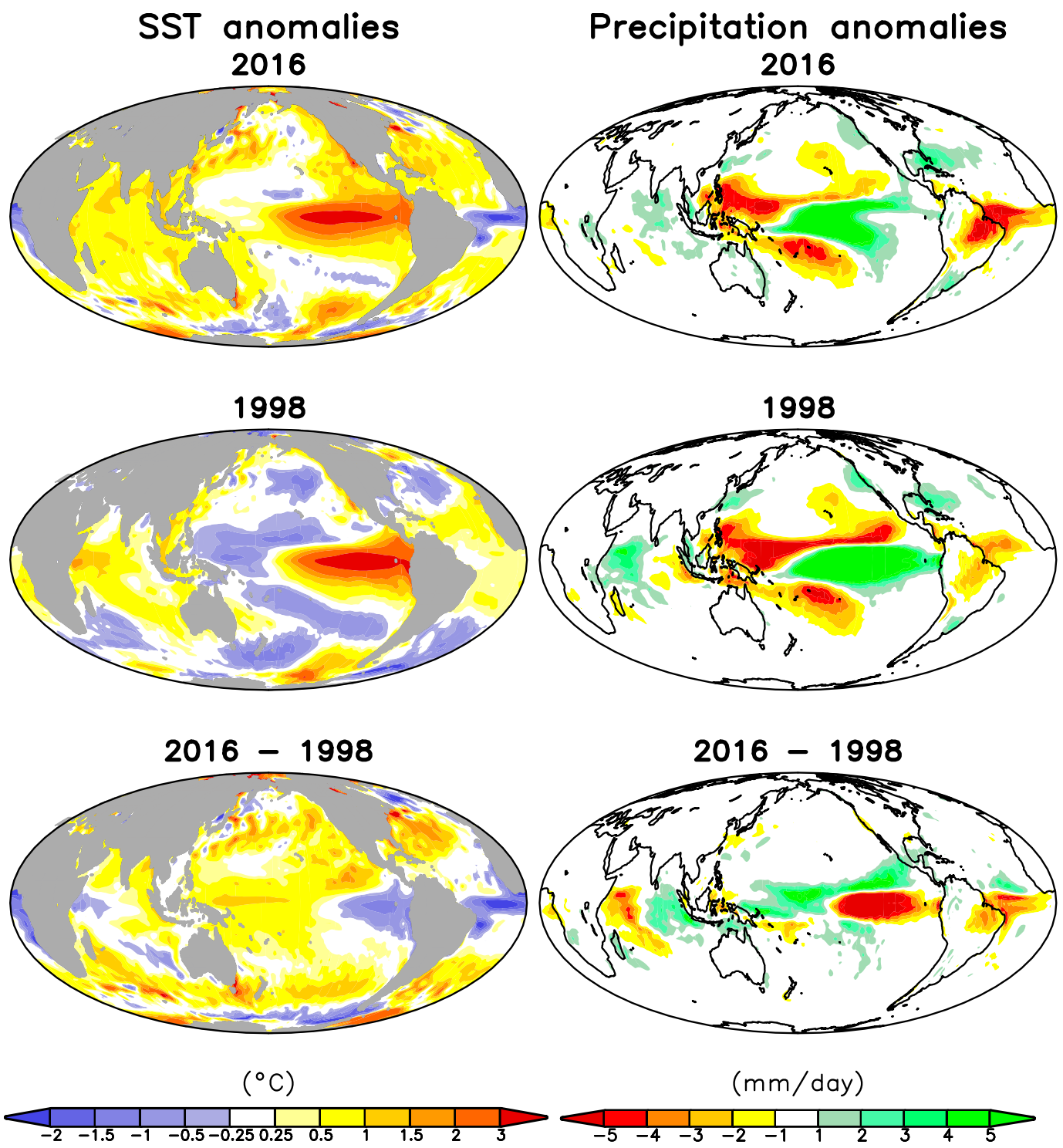

FIG. 9. DJF (left) SST anomalies $\left({ }^{\circ} \mathrm{C}\right)$ and (right) precipitation anomalies $\left(\mathrm{mm} \mathrm{day}^{-1}\right)$ from a 24 -member ensemble-mean CFSv2 seasonal forecast based on November initializations for (top) 2015/16 and (middle) 1997/ 98 and (bottom) the difference.

A second principal finding, offering some evidence for useful long-lead predictability in 2016, was that global boundary forcing likely generated a weaker SCAL wet signal in 2016 compared to 1998 . When averaged over Southern California, the magnitude of the wet signal in all ensembles examined herein was found to be as much as $20 \%-50 \%$ reduced in 2016 compared to 1998 , depending on model. Our analysis of initialized CFSv2 seasonal forecasts revealed skill in capturing this important distinction between the SCAL precipitation signals for the two strong El Niño winters, even though the observed SCAL dryness in an absolute sense was not a long-lead predictable signal. Our results thereby revealed a drawback in relying solely on experiences of the 1998 flooding rains as an analog for surmising 2016 SCAL rains, yet highlighted dynamical model skill in distinguishing climate signals for these two winters.

We discussed possible origins for this weaker SCAL wet signal. A particular flavor of the El Niño region SST forcing in 2016 was argued to not have been a factor. To be sure, large differences in tropical precipitation anomalies between the 2016 and 1998 El Niño events were noted. We demonstrated that the differences between 2016 and 1998 SSTs were largely responsible for the major differences in observed 


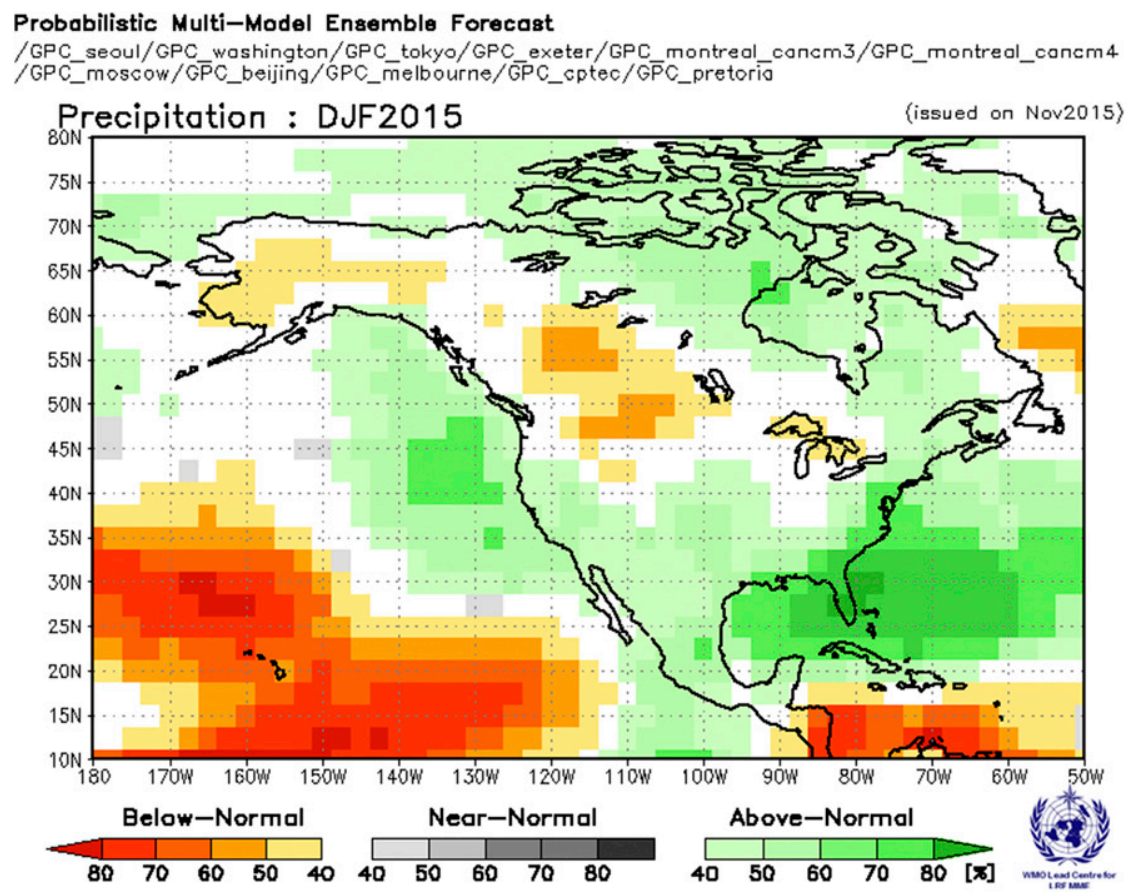

FIG. 10. Ensemble-mean probabilistic DJF 2015/16 North American precipitation predictions based on November 2015 initialization from GPCs comprising 12 operational forecast centers listed at the top of the plot. The data and plots were retrieved from the WMO Lead Center for Long-Range Forecast Multi-Model Ensemble website (https:// www.wmolc.org).

tropical precipitation patterns. These included a $5^{\circ}-10^{\circ}$ poleward displacement of Pacific ITCZ convection and an approximately $20^{\circ}$ longitude westward shift of equatorial Pacific convection-features of the atmospheric response that were plausibly linked to a more CP-like flavor of $2016 \mathrm{El}$ Niño compared to the strong EP articulation of the $1998 \mathrm{El}$ Niño. Convection over the Indian Ocean was also generally more abundant in 2016 compared to 1998, an outward symptom of a strong Indian Ocean dipole mode of 1998 and an overall warmer Indian Ocean in 2016. It was argued, however, based on prior model sensitivity experiments (e.g., Zhang et al. 2016) that the particular flavor of the 2016 El Niño was not likely the cause for the weaker SCAL wet signal relative to 1998 . We did not address which of these various ocean boundary drivers was most important in producing a weaker SCAL wet signal during 2016; for that, additional model experimentation would be required.

The failure of observed SCAL rains in 2016 appears to be mainly due to subseasonal variability that was not constrained by boundary forcing and thus was unpredictable at long lead times. As one line of evidence, we compared CFSv2 initialized seasonal versus monthly predictions of the December-February 2016 averaged SCAL precipitation. These revealed a more skillful prediction in the latter suite of sequential monthly forecasts, which we interpret as due to improved initialization of the atmospheric drivers for the dryness rather than owing to an improved representation of the boundary forcing itself. We also diagnosed the spread among members of the GFSv2 large ensemble simulations, from which we estimated a $5 \%$ probability that SCAL precipitation would be as low as observed, indicating that 2016 failed rains could be reconciled as an occurrence of extreme internal variability relative to the boundary forced signal. By comparison, we found that such a dry winter had a fivefold greater likelihood in the absence of any anomalous boundary forcing. We also note that Madden-Julian oscillation (MJO) activity, the most prominent subseasonal (intraseasonal) signal in the tropics, exhibited a much stronger amplitude in 2016 compared to 1998, and also a much slower phase speed (see appendix C). These additional results suggest that the MJO activity may have favored 2016 SCAL dryness, although the comparison with MJO activity during other strong El Niños (Dole et al. 2018) implies that the intraseasonal behavior in 2016 was unlikely organized by low-frequency SST forcing. 


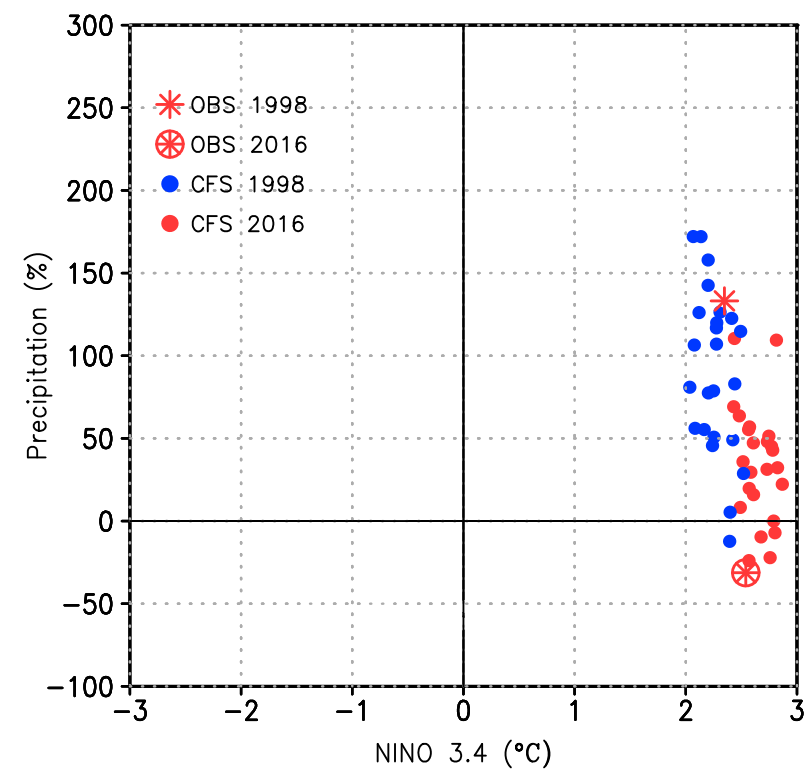

FIG. 11. Scatterplot of SCAL precipitation anomalies (\%, $y$ axis) vs Niño-3.4 $\left(5^{\circ} \mathrm{N}-5^{\circ} \mathrm{S}, 170^{\circ}-120^{\circ} \mathrm{W}\right)$ SST anomalies $\left({ }^{\circ} \mathrm{C}, x\right.$ axis $)$ during DJF. Red and blue dots display each of the 24-member ensemble CFSv2 seasonal predictions (based on November initializations) for 2015/16 and 1997/98 values, respectively. The observed 2015/16 and 1997/98 values are highlighted with a red asterisk inside circle and a red asterisk alone, respectively. Precipitation is averaged over $32^{\circ}-37^{\circ} \mathrm{N}, 125^{\circ}-115^{\circ} \mathrm{W}$.

As a concluding remark, we wish to emphasize that the failed SCAL rains of 2016 were consistent with the probability space of outcomes among the members of the GFSv2 ensemble. Our analysis of the AMIP experiments indicated that the 2016 failed rains were an extreme event in the presence of the particular boundary forcing of that winter. The failed rains were potentially foreseeable at long lead times, but only in a probabilistic manner. We noted in particular that the GFSv2 spread indicated that such an outcome had less than a $2 \%$ probability in the presence of 1998 boundary forcing, compared to triple that much in the presence of 2016 forcing.

The science of seasonal prediction needs to develop capabilities to better express risks of societally important climate events. Official NOAA seasonal outlooks are issued as tercile probabilities that do not offer explicit guidance for extreme events though they could be estimated under certain assumptions of the shape of the probability distribution. Although a thorough analysis is beyond this paper's scope, it is instructive to examine the spread of the 24-member ensemble CFSv2 seasonal predictions for 2016 (based on November initializations), focusing especially on tail behavior. These are shown as scatterplots in Fig. 11, and the 2016 and 1998 forecasts are each plotted. The likelihood of SCAL wet conditions is immediately apparent for both winters. Intriguing from an extreme event forecast perspective is that only the 2016 predictions realize outcomes as dry as observed that winter, whereas only the 1998 predictions realize members as wet as 1998 conditions.

These reforecasts' sample sizes are undoubtedly too small for undertaking a systematic analysis on the predictability of extreme seasonal events. Notwithstanding, the CFSv2 forecasts do indicate extreme event sensitivity to global boundary forcing that distinguished these strong El Niño events. When compared to the observed SCAL rainfall in each winter, the CFSv2 scatter also affirms that both the observed dry conditions in 2016 and very wet conditions in 1998 were each likely made appreciably more extreme by subseasonal variability unrelated to boundary forcing. Indeed, neither of their observed extreme magnitudes was particularly consistent with the magnitude of their respective boundary forced signals. This is consistent with the paper's empirical analysis indicating that the observed 1998 wetness was more than one standard deviation greater than implied by its regression onto Niño-3.4 SST alone, and more than one standard deviation below that regression for 2016. Neither the dryness of SCAL during 2016 nor the extreme wetness in 1998 should be used as a reliable indicator for the expected impact of a strong El Niño, but should rather serve as a reminder that El Niño forcing only modestly constrains the statistics of SCAL winter rainfall.

Acknowledgments. This research was jointly supported by Federally Appropriated Funds and NOAA's Climate Program Office, Climate Variability and Predictability Program (Award GC14-251). We wish to thank Dave Allured for carrying out the large ECHAM5 ensemble runs.

\section{APPENDIX A}

\section{Extreme Events Exceedance Probability}

To estimate the extreme event exceedance probabilities for December-February SCAL precipitation in the GFSv2 AMIP simulations and CFSv2 seasonal forecasts, we first examined various candidate parametric distributions including Weibull, gamma, Gumbel, and normal distributions. The normal distribution was selected as the best fit to GFSv2 simulations and CFSv2 seasonal forecasts judged by the root-mean-square error, graphical quantile-quantile plots, and the KolmogorovSmirnov test. We use 1000 times bootstrap resampling to estimate the sampling uncertainty for the probability of exceedance. A normal distribution was fit to 


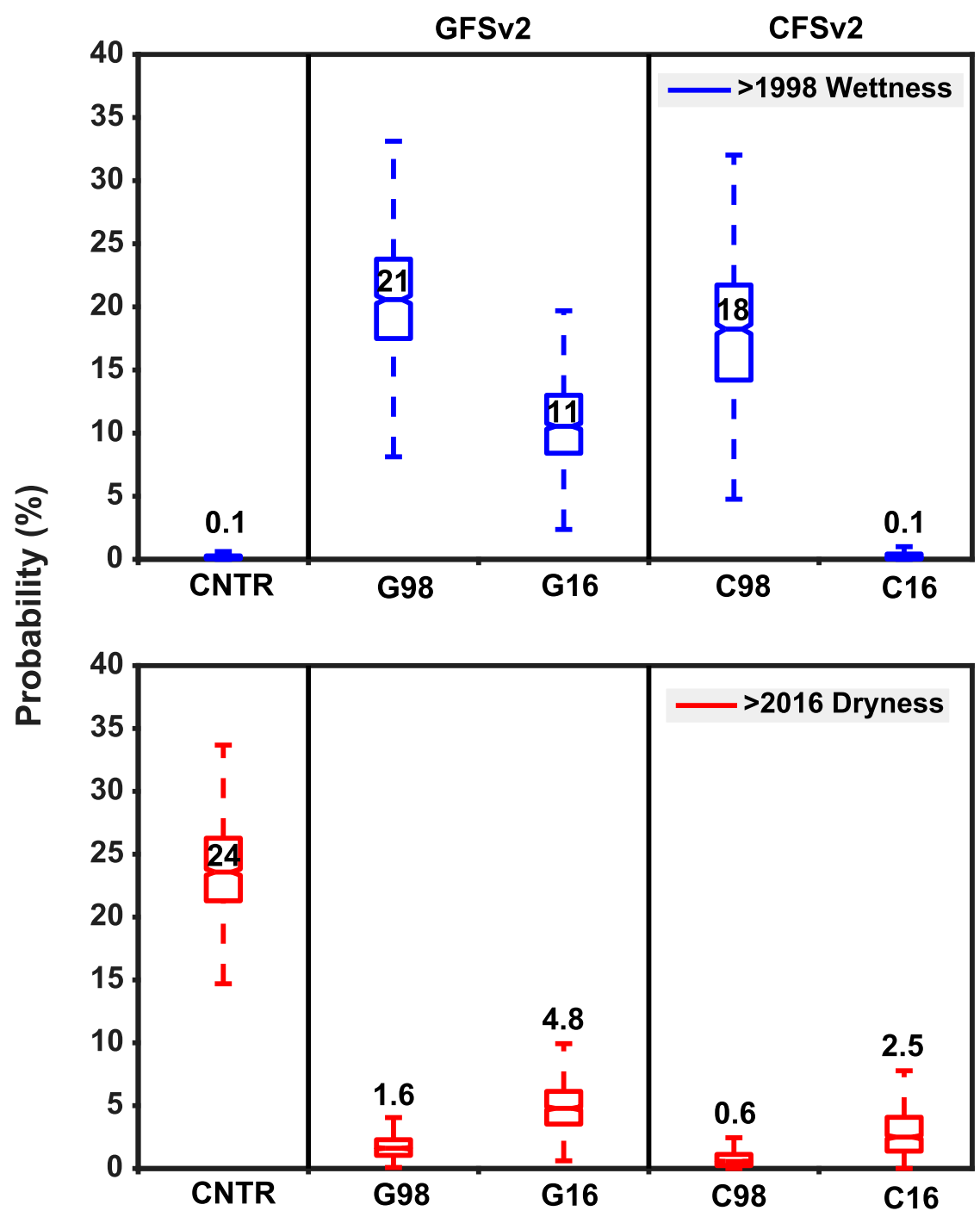

FIG. A1. Box-and-whisker plots of exceedance probabilities (\%) for DJF SCAL precipitation (top) wetter than the observed 1997/98 wetness (blue) and (bottom) drier than the observed 2015/16 dryness (red). Separate columns denote different configurations of SST forcing: GFSv2 climatological (CNTR; left column), GFSv2 1997/98 (G98) and 2015/16 (G16) (center column), and CFSv2 1997/98 (C98) and 2015/16 (C16) (right column). Box-and-whisker plots show the median value (indicated by the center whisker inside the box) and 25th (lower whisker) and 75th (upper whisker) percentiles of exceedance probability based on bootstrap resampling of GFSv2 and CFSv2 ensembles.

each bootstrap sample of size $N$, where $N=50$ for the GFSv2 climatological SST (i.e., CNTR), 1997/98, and 2015/16 AMIP ensembles, and $N=24$ for the CFSv2 $1997 / 98$ and 2015/16 forecast ensembles. Box-andwhisker plots of exceedance probabilities based on these 1000 bootstrap values are presented in Fig. A1. The results show a large probability (about $24 \%$ ) of producing a drier condition than observed 2016 dryness in the GFSv2 climatological SST run (indicated by CNTR), consistent with what can be visually inferred from the smooth histograms (Fig. 5). Climatological SST forcing also has almost zero probability of yielding a wet Southern California condition greater than the observed 1998 wetness, indicating that the latter is more likely driven by ENSO SST forcing rather than by internal atmospheric variability alone. The GFSv2 AMIP simulations show that 2016 global SST has about an $11 \%$ probability of producing a wet Southern California condition greater than the observed 1998 wetness, half of the likelihood resulting from 1998 global SST forcing. There is an about $5 \%$ (under $2 \%$ ) probability of yielding a drier condition than observed 2016 dryness 

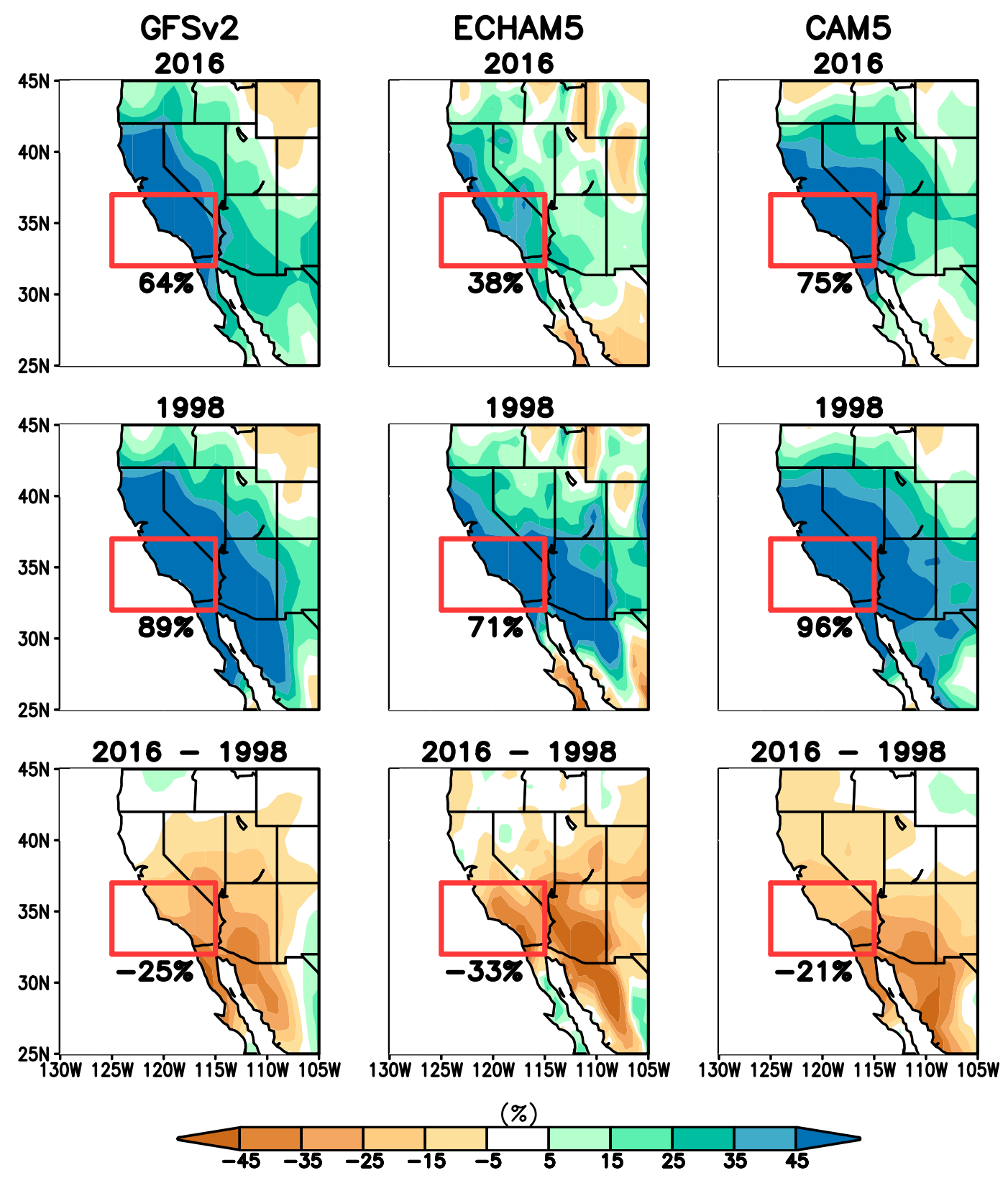

FIG. B1. DJF precipitation anomalies (\% departures) from AMIP simulations of (left) GFSv2, (middle) ECHAM5, and (right) CAM5 for (top) 2015/16 and (middle) 1997/98 and (bottom) the difference. Model results are based on 50-member ensemble for GFSv2 and CAM5 and 30-member ensemble for ECHAM5. Reference period is $1981-2010$. Plotted values are percent departures for the SCAL land area bounded by $32^{\circ}-37^{\circ} \mathrm{N}, 125^{\circ}-$ $115^{\circ} \mathrm{W}$.

under 2016 (1998) global SST forcing. This indicates that the 2016 SCAL dryness was an extreme event in the presence of the particular global forcing of that year, although it was not an extreme event in the presence of climatological boundary forcing. We have repeated the analysis using CFSv2 seasonal forecast and found a similar feature of extreme event sensitivity to global boundary forcings (Fig. A1; right column).

\section{APPENDIX B}

Comparison of Global SST-Forced Impacts on Southern California Precipitation between 2016 and 1998 El Niño Winter across Models

The robustness of different global SST-forced impacts on western U.S. precipitation between 2016 and 1998 El Niño 
(a) MJO Phase 1-2

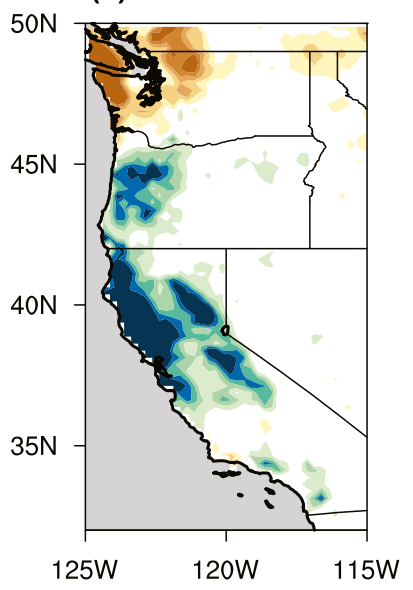

(e) MJO Phase 5-6

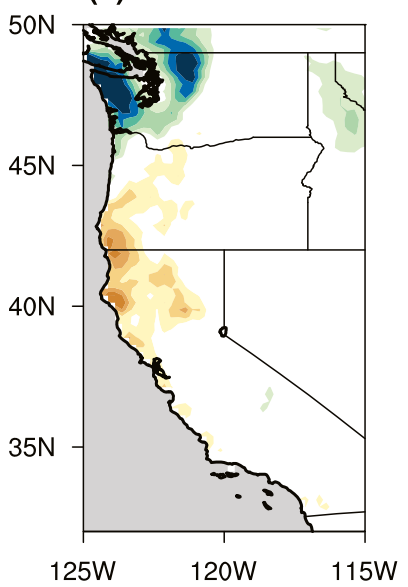

(b) MJO Phase 2-3

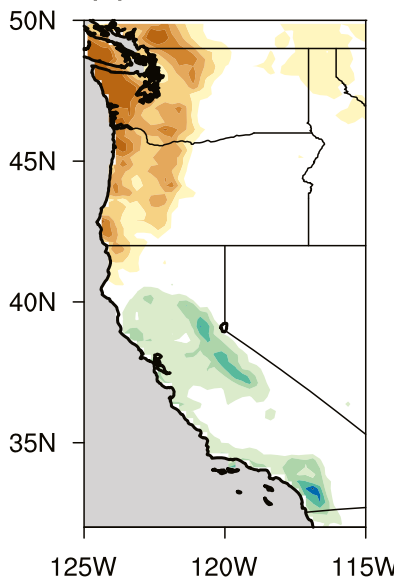

(f) MJO Phase 6-7

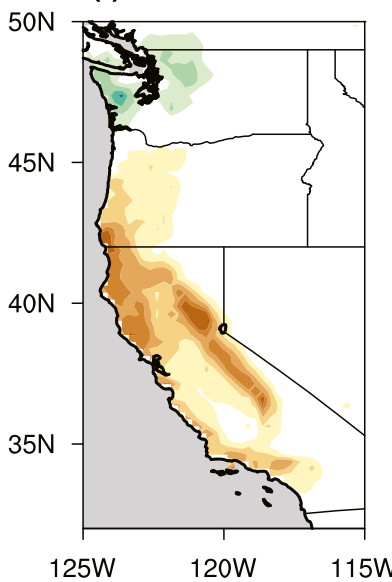

(c) MJO Phase 3-4

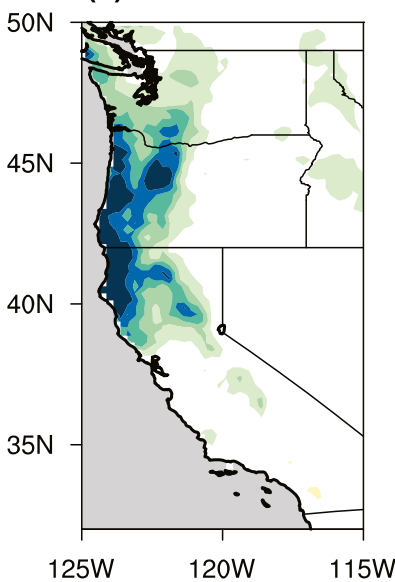

(g) MJO Phase 7-8

$50 \mathrm{~N}$

$45 \mathrm{~N}$

$40 \mathrm{~N}$

$35 \mathrm{~N}$
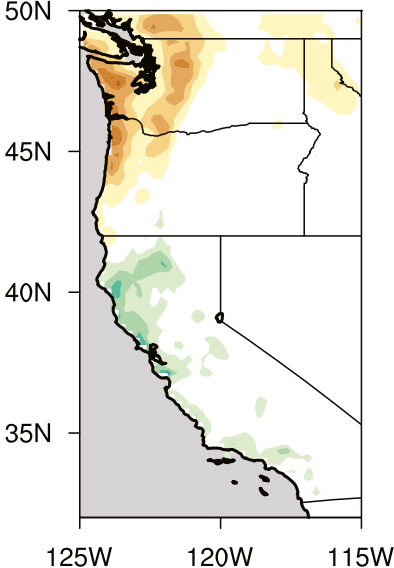

(d) MJO Phase 4-5

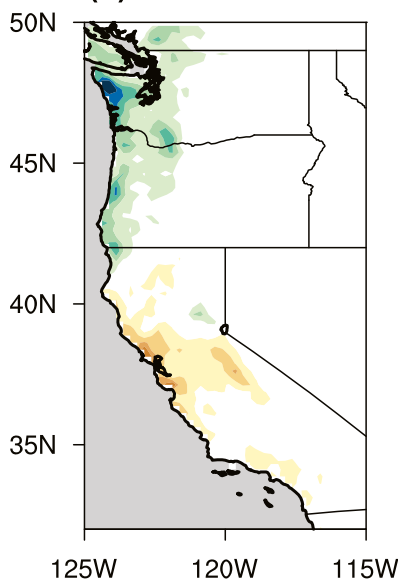

(h) MJO Phase 8-1

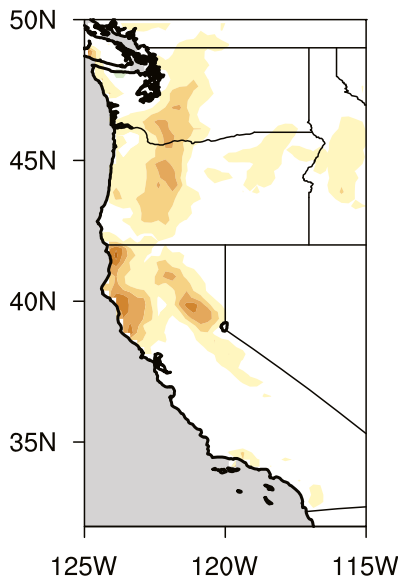

December-February Precipitation Anomaly (mm/day)

\begin{tabular}{|l|ll|l|l|l|l|l|ll|l|}
\hline & & & & & & & & & \\
\hline-2.5 & -2 & -1.5 & -1 & -0.5 & 0.5 & 1 & 1.5 & 2 & 2.5
\end{tabular}

FIG. C1. Daily precipitation anomaly composites during DJF 1981-2016 from the Climate Hazards Infrared Precipitation with Stations (CHIRPS) precipitation dataset (Funk et al. 2015) when the MJO is in the labeled phases for at least 5 days and has a magnitude of 1 or greater.

winter is evaluated by repeating the analysis of Fig. 6 but using different model data. Important in such intercomparison is the use of large-sized ensemble simulations so as not to confound SST-forced patterns with internal atmospheric variability that may dominate the analysis in smallsized ensembles. We have therefore used the data from a 30-member ensemble of similarly designed AMIP experiments derived from the ECHAM5 model and a 50-member ensemble of AMIP simulations from CAM5 model. Figure B1 compares the December-February precipitation anomalies from the GFSv2, ECHAM5, and CAM5 simulations using global SST forcing. All the models show a wet SCAL condition for both winters and a less wet condition in 2016 relative to 1998 . The $25 \%$ reduced wet signal of 2016 compared to 1998 forcing in the GFSv2 model is comparable to the results of the other two models: a $33 \%$ reduction in ECHAM5 and a 21\% reduction in CAM5. This intercomparison reveals that the less wet Southern California signal in 2016 compared to 1998 is robust to structural differences among various atmospheric models.

\section{APPENDIX C}

\section{Comparison of MJO Activity between 2016 and 1998 El Niño Winter}

To explore the possible effect of MJO subseasonal activity on the precipitation variability over the west 

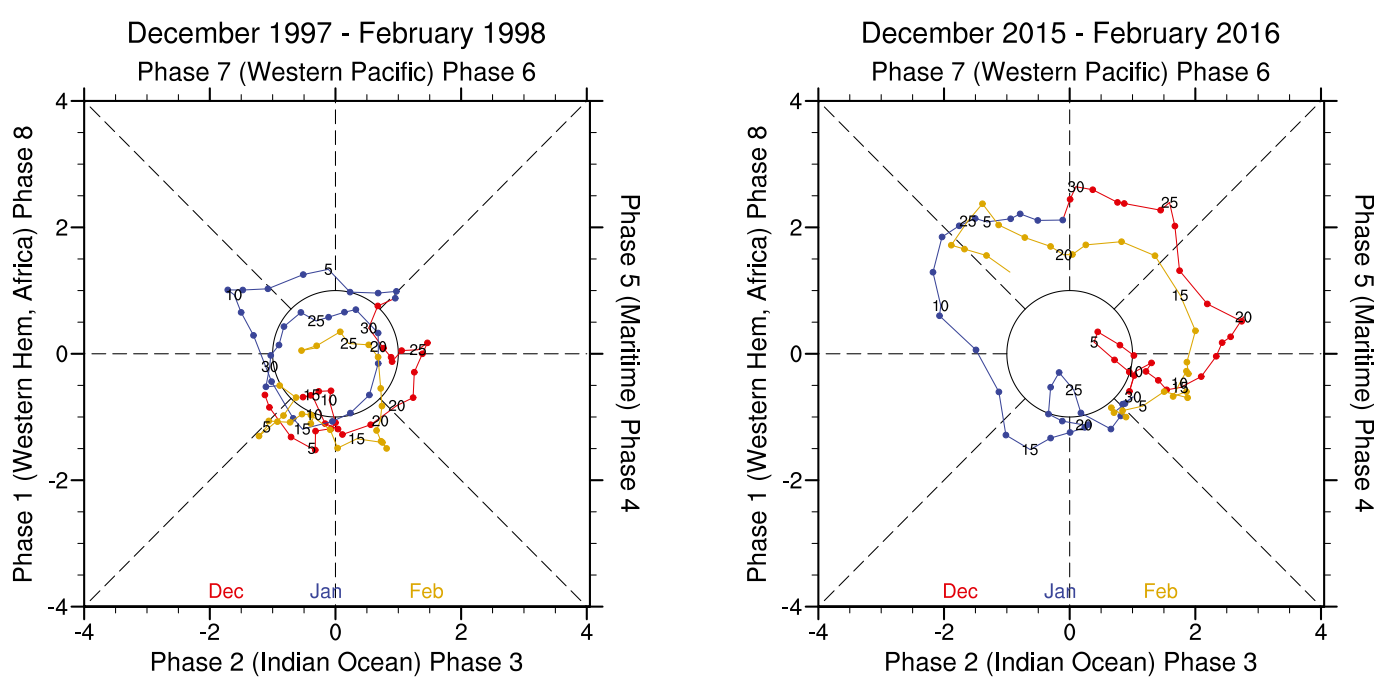

FIG. C2. MJO phase diagrams constructed from the all-season real-time multivariate MJO index (Wheeler and Hendon 2004) during DJF of (left) 1997/98 and (right) 2015/16.

coast of North America including California, we have performed an analysis of the Wheeler-Hendon diagnostic (Wheeler and Hendon 2004) for MJO activity during 2015/16 El Niño, and contrasted with MJO activity during 1997/98 El Niño. Figure C1 shows the composite precipitation anomaly during various phases of the MJO, based on daily data for 1981-2016, and Fig. $\mathrm{C} 2$ shows the real-time multivariate $\mathrm{MJO}$ index for the two El Niño winters. The results indicate a much stronger amplitude MJO activity in 2016 compared to 1998 , and also a much slower phase speed. While the composite rainfall magnitudes indicate that the MJO is unlikely to explain a substantial fraction of the SCAL precipitation conditions in 2016, we note that the prevailing MJO phases 5-7 during the winter of 2016 would be historically associated with dry California conditions. The results are also consistent with the empirical realtime experience during the ENRR (El Niño Rapid Response) Field Campaign in 2016, which encountered unusually intense intraseasonal convection in February 2016, especially compared to prior strong El Niño events (Dole et al. 2018).

\section{REFERENCES}

Barsugli, J. J., and P. D. Sardeshmukh, 2002: Global atmospheric sensitivity to tropical SST anomalies throughout the IndoPacific basin. J. Climate, 15, 3427-3442, https://doi.org/ 10.1175/1520-0442(2002)015<3427:GASTTS>2.0.CO;2.

Changnon, S. A., 1999: Impacts of 1997-98 El Niño generated weather in the United States. Bull. Amer. Meteor. Soc., 80, 1819-1827, https://doi.org/10.1175/1520-0477(1999)080<1819: IOENOG $>2.0 . \mathrm{CO} ; 2$.
Diaz, H. F., and E. R. Wahl, 2015: Recent California water year precipitation deficits: A 440-year perspective. J. Climate, 28, 4637-4652, https://doi.org/10.1175/JCLI-D-14-00774.1.

Dole, R., and Coauthors, 2018: Advancing science and services during the 2015/16 El Niño: The NOAA El Niño Rapid Response Field Campaign. Bull. Amer. Meteor. Soc., https://doi.org/ 10.1175/BAMS-D-16-0219.1, in press.

Funk, C., and Coauthors, 2015: The Climate Hazards Infrared Precipitation with Stations-A new environmental record for monitoring extremes. Sci. Data, 2, 150066, https://doi.org/ 10.1038/sdata.2015.66.

Graham, R. J., and Coauthors, 2011: Long-range forecasting and the global framework for climate services. Climate Res., 47, 47-55, https://doi.org/10.3354/cr00963.

Hoell, A., M. Hoerling, J. Eischeid, K. Wolter, R. Dole, J. Perlwitz, T. Xu, and L. Cheng, 2016: Does El Niño intensity matter for California precipitation? Geophys. Res. Lett., 43, 819-825, https://doi.org/10.1002/2015GL067102.

Horel, J. D., and J. M. Wallace, 1981: Planetary-scale atmospheric phenomena associated with the Southern Oscillation. Mon. Wea. Rev., 109, 813-829, https://doi.org/10.1175/ 1520-0493(1981)109<0813:PSAPAW > 2.0.CO;2.

Hurrell, J., J. Hack, D. Shea, J. Caron, and J. Rosinski, 2008: A new sea surface temperature and sea ice boundary dataset for the Community Atmosphere Model. J. Climate, 21, 5145-5153, https://doi.org/10.1175/2008JCLI2292.1.

Kalnay, E., and Coauthors, 1996: The NCEP/NCAR 40-Year Reanalysis Project. Bull. Amer. Meteor. Soc., 77, 437-471, https:// doi.org/10.1175/1520-0477(1996)077<0437:TNYRP>2.0.CO;2.

Kiladis, G. N., and H. F. Diaz, 1986: An analysis of the 1877-78 ENSO episode and comparison with 1982-83. Mon. Wea. Rev., 114, 1035-1047, https://doi.org/10.1175/1520-0493(1986)114<1035: AAOTEE $>2.0 . \mathrm{CO} ; 2$.

Kug, J.-S., F.-F. Jin, and S.-I. An, 2009: Two types of El Niño events: Cold tongue El Niño and warm pool El Niño. J. Climate, 22, 1499-1515, https://doi.org/10.1175/2008JCLI2624.1.

Kumar, A., and M. P. Hoerling, 1998: Annual cycle of Pacific-North American seasonal predictability associated with different 
phases of ENSO. J. Climate, 11, 3295-3308, https://doi.org/ 10.1175/1520-0442(1998)011<3295:ACOPNA>2.0.CO;2.

Lin, R.-G., II, 2015: 'Massive El Niño is now 'too big to fail,' scientist says." Los Angeles Times, 9 October, accessed 7 June 2017, http://www.latimes.com/local/lanow/la-me-ln-massive-el-ninois-now-too-big-to-fail-scientist-says-20151009-story.html.

Neale, R. B., and Coauthors, 2012: Description of the NCAR Community Atmosphere Model (CAM 5.0). NCAR Tech. Note NCAR/TN-486+STR, 274 pp.

NOAA, 2015: El Niño/Southern Oscillation (ENSO) diagnostic discussion issued 10 September 2015. NOAA, 6 pp., accessed 7 June 2017, http://www.cpc.ncep.noaa.gov/products/analysis_ monitoring/enso_disc_sep2015/ensodisc.pdf.

_ 2017: Billion dollar weather and climate disasters: Table of events. NOAA, accessed 7 June 2017, https://www.ncdc.noaa. gov/billions/events/US/2015.

Paek, H., J.-Y. Yu, and C. Qian, 2017: Why were the 2015/2016 and 1997/1998 extreme El Niños different? Geophys. Res. Lett., 44, 1848-1856, doi:10.1002/2016GL071515.

Redmond, K. T., and R. W. Koch, 1991: Surface climate and streamflow variability in the western United States and their relationship to large-scale circulation indices. Water Resour. Res., 27, 2381-2399, https://doi.org/10.1029/91WR00690.

Roeckner, E., and Coauthors, 2003: The atmospheric general circulation model ECHAM5. Part I: Model description. Max Planck Institute for Meteorology Rep. 349, 127 pp.

Ropelewski, C. F., and M. S. Halpert, 1986: North American precipitation and temperature patterns associated with the El Niño/Southern Oscillation (ENSO). Mon. Wea. Rev., 114, 2352-2362, https://doi.org/10.1175/1520-0493(1986)114<2352: NAPATP $>2.0 . \mathrm{CO} ; 2$.

Saha, S., and Coauthors, 2014: The NCEP Climate Forecast System version 2. J. Climate, 27, 2185-2208, https://doi.org/10.1175/ JCLI-D-12-00823.1.

Saji, N. H., B. N. Goswami, P. N. Vinayachandran, and T. Yamagata, 1999: A dipole mode in the tropical Indian Ocean. Nature, 401, 360-363, doi:10.1038/43854.

Schneider, U., A. Becker, P. Finger, A. Meyer-Christoffer, M. Ziese, and B. Rudolf, 2014: GPCC's new land surface precipitation climatology based on quality-controlled in situ data and its role in quantifying the global water cycle. Theor. Appl. Climatol., 115, 15-40, https://doi.org/10.1007/ s00704-013-0860-x

Schonher, T., and S. E. Nicholson, 1989: The relationship between California rainfall and ENSO events. J. Climate, 2 1258-1269, https://doi.org/10.1175/1520-0442(1989)002<1258: TRBCRA $>2.0 . \mathrm{CO} ; 2$.

Seager, R., M. Hoerling, S. Schubert, H. Wang, B. Lyon, A. Kumar J. Nakamura, and N. Henderson, 2015: Causes of the 2011 to 2014 California drought. J. Climate, 28, 6997-7024, https:// doi.org/10.1175/JCLI-D-14-00860.1.

Simmons, A. J., J. M. Wallace, and G. W. Branstator, 1983 Barotropic wave propagation and instability, and atmospheric teleconnection patterns. J. Atmos. Sci., 40, 13631392, https://doi.org/10.1175/1520-0469(1983)040<1363: BWPAIA $>2.0 . \mathrm{CO} ; 2$.

Wang, C., and R. H. Weisberg, 2000: The 1997-98 El Niño evolution relative to previous El Niño events. J. Climate, 13, 488-501, https://doi.org/10.1175/1520-0442(2000)013<0488: TENOER $>2.0 . \mathrm{CO} ; 2$.

Wheeler, M. C., and H. H. Hendon, 2004: An all-season real-time multivariate MJO index: Development of an index for monitoring and prediction. Mon. Wea. Rev., 132, 1917-1932, https://doi.org/10.1175/1520-0493(2004)132<1917: AARMMI $>2.0 . \mathrm{CO} ; 2$.

Xie, P., and P. A. Arkin, 1997: Global precipitation: A 17-year monthly analysis based on gauge observations, satellite estimates, and numerical model outputs. Bull. Amer. Meteor. Soc., 78, 2539-2558, https://doi.org/10.1175/1520-0477(1997)078<2539: GPAYMA $>2.0 . \mathrm{CO} ; 2$.

Zhang, T., J. Perlwitz, and M. P. Hoerling, 2014: What is responsible for the strong observed asymmetry in teleconnections between El Niño and La Niña? Geophys. Res. Lett., 41, 1019-1025, https://doi.org/10.1002/2013GL058964.

—, M. P. Hoerling, J. Perlwitz, and T. Xu, 2016: Forced atmospheric teleconnections during 1979-2014. J. Climate, 29, 2333-2357, https://doi.org/10.1175/JCLI-D-15-0226.1. 